\title{
Influence of particle aggregation on the tephra dispersal and sedimentation from the October 8, 2016, eruption of Aso volcano
}

\author{
Tomohiro Tsuji ${ }^{*} \mathbb{D}$, Naoki Nishizaka² and Kozo Ohnishi ${ }^{2}$
}

\begin{abstract}
The phreatomagmatic eruption at Aso volcano on October 8, 2016, released PDC and fallout up to $320 \mathrm{~km}$ from the vent, providing an opportunity to study the dispersal and sedimentation of tephra bearing wet and dry aggregates. We investigated fresh air-fall tephra and conducted both dry- and wet-sieving to assess the size distribution of both aggregate-bearing deposits on the ground and particles in the plume prior to aggregation. The tephra was asymmetrically distributed in the ENE direction, with a relatively wide distribution and small maximum grain sizes north of the depositional axis, reflecting different wind directions at each altitude. The secondary accumulation maxima at 4-8 km NE from the vent was characterized by the segregation of lapilli followed by accretionary pellets that were rapidly created by aggregation in the wet plume, thereby enhancing the removal of airborne ash. Coalesced aggregates possibly arose from salt precipitation processes. For dry aggregates fallen in medial-to-distal regions, observed deposition duration and fall velocity calculations concluded that fine ash was deposited not as individual particles but as aggregates. Most grain-size distributions along the dispersal axis based on the two sieving methods used were multimodal, with the coarser mode fining according to distance from the vent and the finer mode stabilizing at around $4 \varphi$; this is interpreted as resulting from the mixture of grain-size distributions with different origins, i.e., the normal settling of individual clasts and particle aggregation. The wet-sieved total grain-size distribution included 20.4 wt\% fine ash compared with only $2.4 \mathrm{wt} \%$ fine ash in the dry-sieved distribution, suggesting that aggregated particles accounted for $18 \mathrm{wt} \%$ of the deposit. Total grain-size distributions based on wet-sieving showed extremely poor sorting that could be explained by the following causes: the release of coarse-grained ejecta originating from the host rock of the crater, fine particles due to fragmentation from a phreatomagmatic eruption, the supply of water and salt from the crater to the plume, and aggregation enhancement of the fine ash on the ground, reflecting the effect of the crater lake as external water source.
\end{abstract}

Keywords: Tephra dispersal, Sedimentation, Grain-size distribution, Aggregation, Phreatomagmatic eruption, Aso volcano

\footnotetext{
*Correspondence: t-tsuji@yamaguchi-u.ac.jp

1 Graduate School of Sciences and Technology for Innovation, Yamaguchi University, 1677-1 Yoshida, Yamaguchi City, Yamaguchi 753-8512, Japan Full list of author information is available at the end of the article
}

\begin{abstract}
Introduction
Explosive volcanic eruptions generate ejecta of various sizes that are carried up within the convective plume, dispersed by the surrounding wind field and deposited on land, forming tephra-fall deposits. The transport and sedimentation processes of tephra particles are complicated due to turbulence in the plume and atmosphere, both
\end{abstract}


of which exhibit a variety of conditions, particularly in terms of physical and chemical interaction between particles. In particular, most volcanic ash finer than $125 \mu \mathrm{m}$ has been considered to settle out of the atmosphere as particle aggregates with higher settling velocities than the individual constituent particles (Carey and Sigurdsson 1982; Sorem 1982; Lane et al. 1993). Particle aggregation and meteorological effects can cause the secondary thickening of deposits (e.g., Cashman and Rust 2016). Aggregation thus exerts a first-order control on the dispersal of fine ash within eruption clouds, however, the precise physical and chemical processes involved and the effect of tephra sedimentation have never been completely constrained (Brown et al. 2012).

The atmospheric residence time of fine ash determines whether it poses a hazard to aviation (Casadevall 1994). Ash falls can also harm local environments and infrastructure (Stewart et al. 2006; Brown et al. 2012). Ash aggregation should thus be accounted for when developing our understanding of the transport of volcanic particles. Ash dispersal and sedimentation are not straightforward, mostly due to (1) the poor exposure of most tephra deposits, such that important areas are often difficult to access; (2) variable rates of deposit erosion; (3) difficulty in recognizing and correlating proximal and distal deposits, and (4) sequences of multiple eruptive styles and processes that complicate the understanding of individual deposits (Bonadonna and Houghton 2005; Bonadonna et al. 2015a; Murrow et al. 1980; Costa et al. 2016).

In this study, we investigated grain-size variations in a deposit from a discrete phreatomagmatic eruption of Nakadake crater, Aso volcano, Japan, on October 8, 2016 (Fig. 1). The eruption produced a simple eruptive column that dispersed tephra ENE along the Japanese island arc such that we were able to sample the deposit more than $300 \mathrm{~km}$ away from the vent (Fig. 2). This eruption is therefore an ideal model for studying processes of tephra dispersal and sedimentation using the total grain-size distribution of the deposit. By correlating aggregate characteristics and tephra size variations with their distance from the vent, we provide new information regarding the aggregation of tephra during sedimentation.

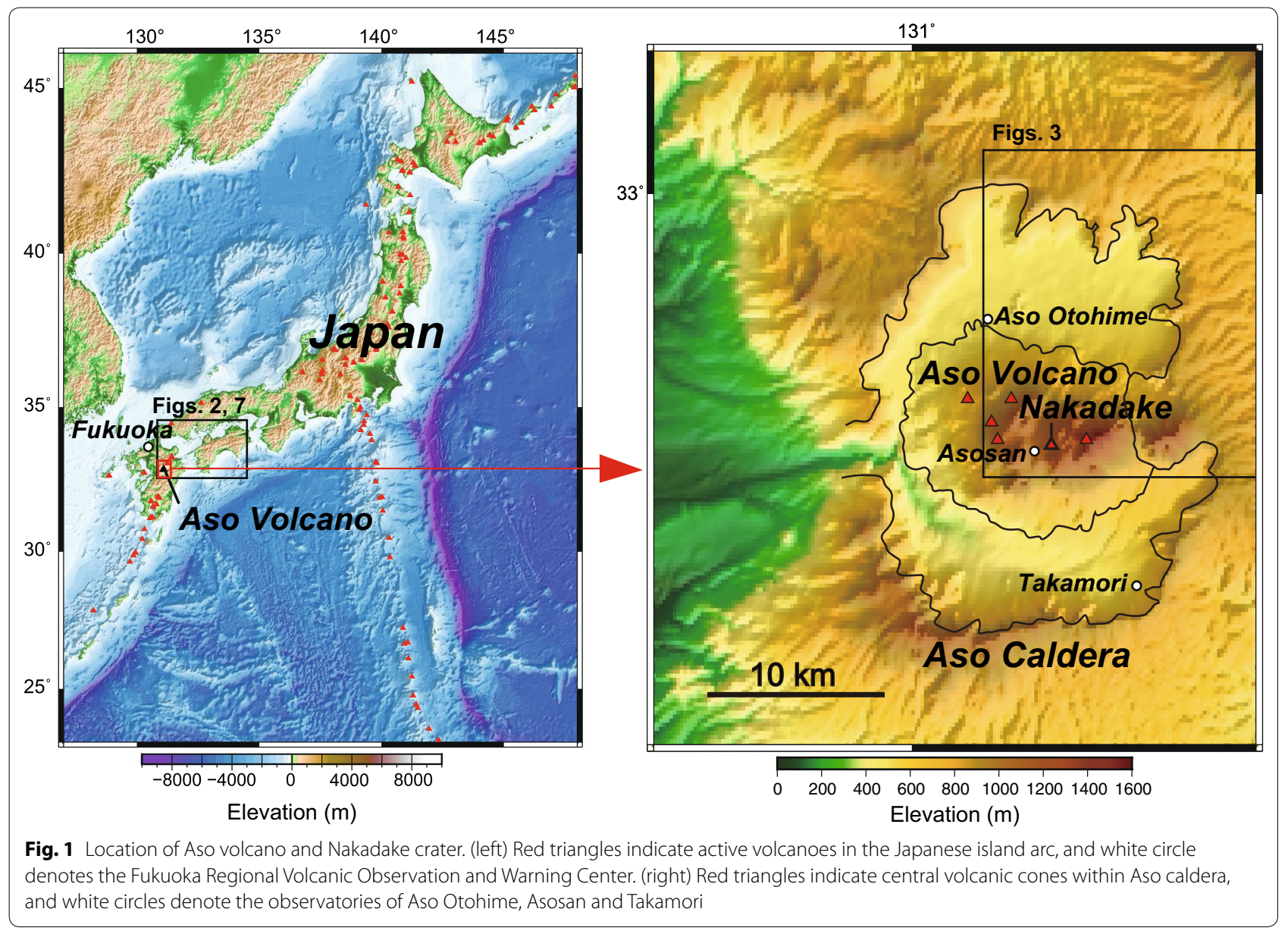




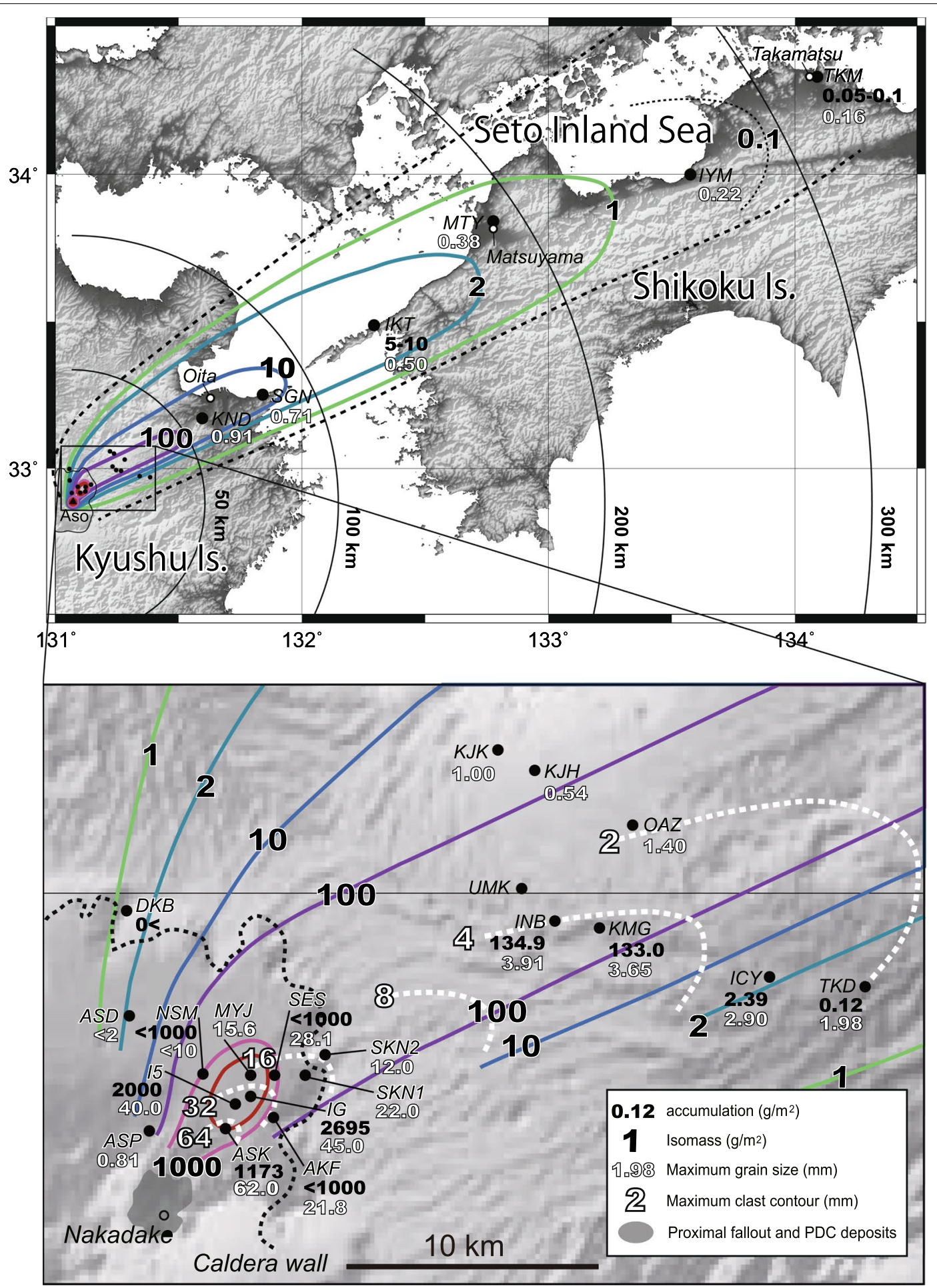

Fig. 2 Distribution of fallout deposits resulting from the 8 October $2016 \mathrm{Mt}$ Aso eruption within approximately $330 \mathrm{~km}$ (a) and $30 \mathrm{~km}$ from the vent (b). The accumulation per unit area (black characters, $\mathrm{g} / \mathrm{m}^{2}$ ) and maximum observed grain size (white characters, mm) are indicated for each sampling site (black dots). The maximum grain size of the ash fallen at the MTY site is based on our measurements from Fig. 4l of Sugawara (2017). The interpreted isomass (red to pale green-shaded areas, $\mathrm{g} / \mathrm{m}^{2}$ ) and maximum clast contours (white dashed lines, mm) were hand drawn to fit the observed data. The black dashed line in the top figure indicates the zero accumulation line of Fukuoka Regional VOWC (2016), which was used in the total grain-size calculation. Circles represent radii of 50, 100, 200, and $300 \mathrm{~km}$ from Nakadake crater. The black dashed line in b indicates the Aso caldera wall 


\section{Geological setting and the October 8, 2016 eruption \\ Aso volcano and Nakadake crater}

Japan's 24-km-wide Aso caldera in Kyushu Island (Fig. 1) has been active since its first caldera-forming eruption (270 ka; Japan Meteorological Agency and Volcanological Society of Japan (2013). Several post-caldera cones, with compositions ranging from basalt to rhyolite, have formed near the center of the caldera since the last caldera-forming eruption (Ono and Watanabe 1985) at 90 ka (Japan Meteorological Agency and Volcanological Society of Japan 2013). Nakadake (1506 m in altitude) is an active basaltic to basaltic-andesitic stratocone and has been most active of the 17 central cones during the past 2000 years (Global Volcanism Program (2013). During the last 6000 years, the dominant eruptive products at Nakadake have been black ash with some scoria, indicating that its main eruption style has been continuous ash emission, which is referred as "ash eruption" (Ono et al. 1995). Only one crater (First crater) in Nakadake has been active during the last 80 years (Japan Meteorological Agency (JMA) and Volcanological Society of Japan (VSJ) 2013) and the most recent activity includes several ash emissions that occurred in 2003-2005 and 2014-2016 (JMA and VSJ 2013). The summit crater of Nakadake hosts a hot, acidic crater lake that submerges the crater bottom during periods of quiescence; the water level decreases during periods of volcanic unrest (e.g., Kawakatsu et al. 2000).

\section{October 8, 2016 Aso Nakadake eruption}

A small initial eruption occurred at First crater at 21:52 (all times reported are JST, UTC + 9) on October 7, 2016 (Fukuoka Regional Volcanic Observation and Warning Center (2016). Approximately $4 \mathrm{~h}$ later, an explosive phreatomagmatic eruption occurred at 01:46 on October 8, 2016 (Sato et al. 2018). This eruption was not captured on camera, but was detected by weather radar equipment (Weathernews Inc. 2016; Sato et al. 2018). The duration of the eruption was estimated to be 160-220 s based on seismic records (Shimbori 2017) and the plume rose to approximately $8 \mathrm{~km}$ above sea level (a.s.l.) by 01:58 (Fig. 3; Weathernews Inc. 2016). Based on the infrared band of Himawari-8, the plume is assumed to have reached a maximum height of $11.9 \mathrm{~km}$ a.s.l. (Tokyo Volcanic Ash Advisory Center 2016; Sato et al. 2018). Volcanic ash in the atmosphere flowed in a northeast direction at lower (below $2 \mathrm{~km}$ a.s.l.) to middle altitude (2-8 km a.s.l.), and in an east-northeast direction at the middle-to-higher altitude (8-12 km a.s.l.) (Sato et al. 2018). The plume was thus influenced by various wind directions and speeds at lower, middle and higher altitudes $(2-15 \mathrm{~m} / \mathrm{s}$ from the southeast-southwest, $9-27 \mathrm{~m} / \mathrm{s}$ from the southwest and $22-39 \mathrm{~m} / \mathrm{s}$ from the west, respectively, at 21:00 on October 7 and 09:00 on October 8 at Fukuoka city (Additional file 1, see Fig. 1 for locality; Japan Meteorological Agency 2019. At ground level around Mt. Aso, wind was blowing from the SE with speeds of $8.3 \mathrm{~m} / \mathrm{s}$, the temperature was $17.2{ }^{\circ} \mathrm{C}$, it was very humid ( $100 \%$ humidity), and the precipitation was $0.0 \mathrm{~mm}$ at the observatories of Aso Otohime and Takamori at 01:40 on October 8 (see Fig. 1 for localities; Japan Meteorological Agency 2019). The plume was strongly affected by westerly winds at middle-tohigh altitudes and thus drifted more than $300 \mathrm{~km}$ ENE. Tephra deposition started at approximately 01:58 at Ichinomiya ( $7 \mathrm{~km} \mathrm{NE}$ ) based on our interview survey, before 02:30 at Oita (63 km ENE), around 05:00 at Matsuyama (190 km ENE), and before 08:00 at Takamatsu $(318 \mathrm{~km}$ ENE) (see Fig. 2 for localities; Shimbori 2017). We also observed the ashfall at site IKT (132.2 km from the vent) at 04:39, where the short period of sedimentation lasted approximately $5 \mathrm{~min}$ (see Fig. 2 for locality). Around $1.8 \times 10^{8} \mathrm{~kg}$ of volcanic ash (Miyabuchi et al. 2017) fell on the NE side of the volcano and volcanic ash was observed at Kyushu Island, Shikoku Island, and around the Seto Inland Sea (Shimbori 2017; Sato et al. 2018). The summit area became covered with thick tephra deposits, approximately $1 \mathrm{~m}$ thick at the SW crater rim, amounting to approximately $4.5 \times 10^{8} \mathrm{~kg}$ of eruptive material around the crater, including pyroclastic density current deposits (Miyabuchi et al. 2017) and the crater lake still existed $8 \mathrm{~h}$ after the eruption (Fukuoka Regional VOWC 2016). The total amount of ejecta associated with the eruption is estimated to be approximately $6.0-6.5 \times 10^{8} \mathrm{~kg}$ (Miyabuchi et al. 2017), i.e., as large as the recent major eruptions on September 6, 1979, and April 20, 1990 (Miyabuchi et al. 2017). Based on the total eruptive mass and eruption duration, the eruption rate is calculated to be 2.7$4.1 \times 10^{6} \mathrm{~kg} / \mathrm{s}$ (Miyabuchi et al. 2017). As of October 2018, no further explosive eruptions have been recorded (Global Volcanism Program 2013).

\section{Methods \\ Field investigation}

Seven hours after the eruption, we started a field campaign to characterize the tephra-fall deposits in terms of mass-per-unit area, grain size, components, particle aggregation, stratigraphy and distribution (Additional file 2). We classified grain-size divisions based on the schemes of Cas and Wright (1987) and Cashman and Rust (2016). Aggregates were described, following total grain-size distribution Brown et al. (2012), as accretionary pellets (poorly structured pellets, AP1, and liquid pellets, AP3) and particle clusters (ash clusters, PC1, and coated particles, PC2). At site IKT (Fig. 4), ash fall was 

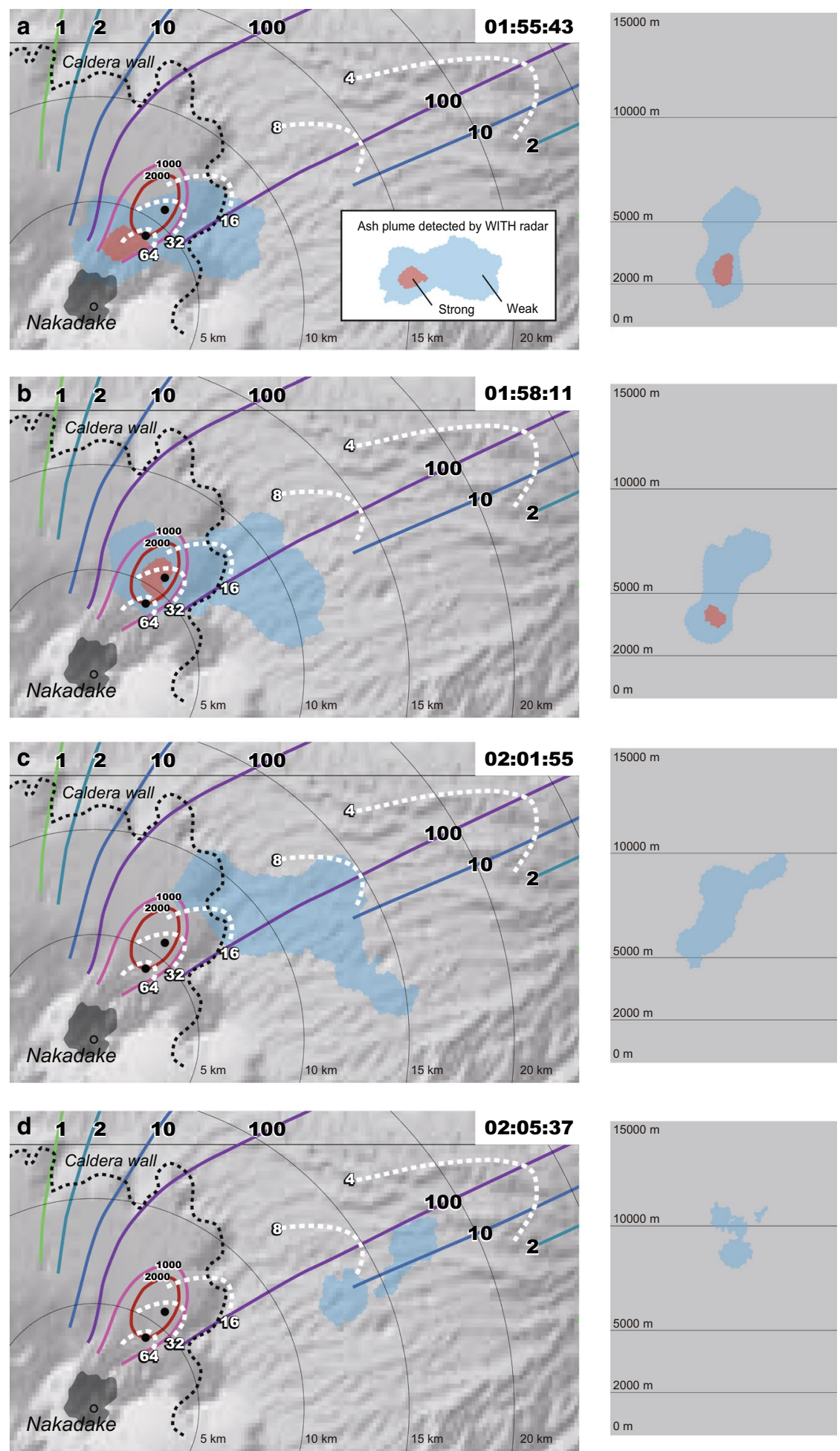

Fig. 3 Plume dimensions as sketched from images at a 01:55, b 01:58, c 02:01 and d 02:05 on October 8 from the trial operation of WITH radar observation images (Weathernews Inc. 2016). The strong and weak reflectivity of the radar are shown by orange and light blue colors. The summit area covered by proximal fallout and pyroclastic density current deposits is shown in gray. Black and white bold numbers denote isomass $\left(\mathrm{g} / \mathrm{m}^{2}\right)$ and maximum clast contours ( $\mathrm{mm}$ ), respectively, which are equivalent to those of Fig. 2 

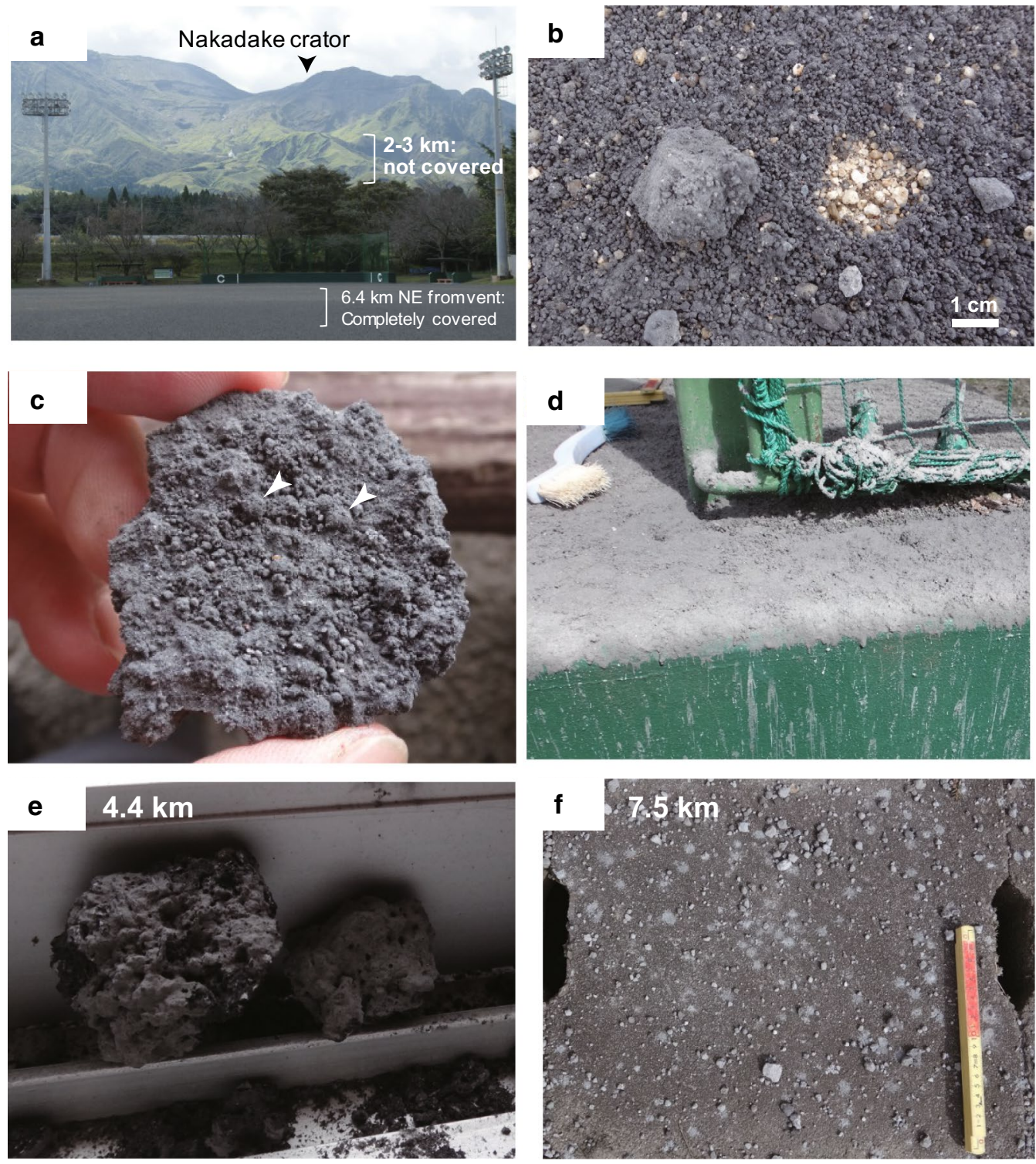

Fig. 4 Field photographs of proximal deposits within $7 \mathrm{~km}$ of the vent. a View of Nakadake crater from site IG ( $6.4 \mathrm{~km}$ from vent). The ground 2-3 km from the vent remained green, suggesting incomplete coverage by the gray fall deposit. $\mathbf{b}$ The baseball field at site IG was completely covered by the gray fall deposit. Note the absence of the deposit where we removed a coarse lapilli particle (white area to the right of center), suggesting that coarse lapilli were among the first clasts to fall. Scale bar $1 \mathrm{~cm}$. c Upper surface of a lapilli particle at site IG, containing accretionary pellets of type AP1 (white arrow marks) and AP3. d AP3 deposited on the upper surface and the side of a concrete wall at the baseball field (site IG). AP1/2 were covered by AP3, although particles that fell under the net fence were not covered. e Coarse lapilli particles that broke a window and fell inside a building at the Aso youth intercommunion house (site ASK, $4.4 \mathrm{~km}$ from vent). Fine ash particles coated the lapilli particles, although to a lesser degree less than those that fell outside the building. $\mathbf{f}$ Lapilli and AP3 that fell at site SES ( $7.5 \mathrm{~km}$ from vent). Fewer AP3 were deposited relative to site IG $(6.4 \mathrm{~km})$ and the ground was not completely covered by the fall deposit. All locations are shown in Fig. 2

observed at 04:39, approximately three hours after the eruption (Additional file 2). Tephra particles were collected using a rainwater-filling waterproof polyester sheet which covered a container at site TKM, $323 \mathrm{~km}$ from the vent (Fig. 2). Contours of isomass and maximum clast size were hand drawn based on measured accumulation per unit area and maximum observed clast size, respectively (Fig. 2).

In total, we studied tephra deposits from the eruption at 17 sites, ranging from 4 to $323 \mathrm{~km}$ from the vent (Additional file 2). 15 tephra samples were collected for grain-size analyses out of which nine were collected b 
they authors (localities for which survey times/dates are listed in Additional file 2) and the other six were collected by our collaborators $(\mathrm{H}$. Takano, T. Nagata and T. Yamane; localities for which survey times/dates are not listed). In addition, we added the maximum grain size of the ash fallen at the MTY site (Fig. 2), based on Sugawara (2017).

\section{Grain-size analyses, microscope observation and density measurement}

Nine tephra samples were collected before a period of precipitation began at 13:30 October 8 , and were dried in an oven at $60{ }^{\circ} \mathrm{C}$ for 1 day before being dry-sieved down to $4 \phi\left(\phi=-\log _{2} D\right.$, where $D$ is the particle diameter in millimeters) at $1 \phi$ intervals. 15 samples were wet-sieved down to $4 \phi$. Wet-sieved ash fractions finer than $4 \phi$ were analyzed down to $11 \phi$ using a Microtrac MT3000 laser diffraction particle size analyzer in dispersion mode, which provided measurements from 0.021 to $1408 \mu \mathrm{m}$ assuming an ash refractive index of 1.51 and a nonspherical grain shape; volume fractions were converted into weight fractions assuming constant particle density, as is appropriate for particles $<63 \mu \mathrm{m}$ (Eychenne and Le Pennec 2012). For selected samples, overlapping laser diffraction and wet-sieving analyses between 1 and $4 \phi$ were used to validate and merge the results of the two techniques. Mdphi and sorting were calculated for all samples according to Inman (1952).

We identified particle clusters (PC1 and PC2) using light microscopy, and accretionary pellets, except liquid pellets, using scanning electron microscopy (SEM) backscattered electron (BSE) imaging to identify AP1 and AP2.

We selected samples for density measurements from three representative proximal and distal sites along the dispersal axis, which was taken as the line connecting the largest curvature point on each contour line (Fig. 2). The samples were dried following the same procedure as for the grain-size analyses and were weighed in the laboratory. Sample volumes were measured in a water-filled cylinder to calculate the average density of clasts between -3 and $5 \phi$.

\section{Total grain-size analysis}

Calculations of total grain-size distribution (TGSD) depend strongly upon the number and distribution of sampling sites used (Bonadonna and Houghton 2005). We used nine and 15 sites to calculate the TGSD of dryand wet-sieved samples, respectively (totaling 15 sites, since the wet- and dry-sieved samples shared nine common sites). Grain-size analyses were conducted according to the Voronoi tessellation technique using TOTGS software (Biass and Bonadonna 2014) in order to investigate individual subpopulations. TGSDs obtained using the Voronoi technique are less dependent on the position of the "zero accumulation line" than those obtained by other techniques (Volentik et al. 2010). We defined the zero accumulation line based on the Fukuoka Regional VOWC (2016) (black dashed line in the top of Fig. 2). Additionally, we analyzed grain-size distributions using DECOLOG 5.6.1 (Borselli and Sarocchi 2004), which is based on an iterative algorithm for optimizing nonlinear fitting of log-normal functions to calculate mean particle size, standard deviation $\left(\sigma_{\phi}\right)$ and asymmetry; for this, we used two- and three-component log-normal distributions for the dry- and wet-sieved TGSDs, respectively.

\section{Results}

\section{Distribution of tephra-fall deposits}

The mass loading was highest around the vent and, where the ground was completely covered by thick deposits, up to $1 \mathrm{~m}$ at the southwest rim of the crater (Figs. 2, 3; JMA 2016, Miyabuchi et al. 2017). In the most proximal area we observed, around $2-3 \mathrm{~km} \mathrm{NE}$ of the vent, the ground remained green (Fig. 4a), suggesting incomplete coverage by the fall deposit. Proximal to the vent $(4-10 \mathrm{~km})$, the deposit was distributed in a narrow zone to the NENNE, which was completely covered by the fall deposit (Fig. 4a, b). The maximum accumulation $\left(2695 \mathrm{~g} / \mathrm{m}^{2}\right)$ was recorded $6.4 \mathrm{~km}$ NE from the vent (site IG, Fig. 2). From the area around site IG to the distal area, the accumulation per unit area decreased again (Fig. 2). We also noted a shift of the deposit axis from NE to ENE around $10 \mathrm{~km}$ from the vent (Additional file 2, Figs. 2, 3). Furthermore, the axis of the maximum clast contour was offset south of the dispersal axis (Figs. 2, 3). These features are consistent with weather radar observations indicating that the plume drifted NE at lower to middle altitudes and ENE-E in middle-to-higher altitudes (Additional file 1, Fig. 3).

Medial to distal ash fall was observed at nine localities beyond Aso caldera, including two sites on Shikoku Island (Fig. 2). The isomass map indicates narrow crosswind deposition compared with broader down-wind deposition (Fig. 2). With the exception of the near-vent region, no sedimentation in the upwind region has been reported (Fig. 2).

\section{Deposit characteristics}

In proximal areas, the deposit comprises lapilli-bearing ash fall overlain by AP1 and AP3 (Fig. 4b-e, Additional file 2). At site ASK, lapilli coarser than $60 \mathrm{~mm}$ in diameter were not found on concrete, but were found on grass. This suggests that clast breakage occurred on the ground. Measuring the maximum grain size on grass, we found that the amount of AP1 and AP3 decreased from site IG (6.4 $\mathrm{km}$ from the vent) to site SES (7.5 km from the vent) 
(Fig. 4f). In localities IG and I5, lapillus, AP1 or 2, and 3 coalesced and formed platy fragments with flat bottoms (Fig. 4c). In medial areas, the deposit comprised mainly fine lapilli-bearing materials with AP1 or 2, and 3, and PC1 and 2 (Additional file 2). Distally, the deposit was dominated by PC2 with small amounts of PC1 (Additional file 2).

The aggregates comprised a significant volume of tephra regardless of the distance from the vent (Additional file 2), suggesting that particle aggregation was an important process during the 2016 eruption. However, the dominant type of aggregate changed with distance from the vent: proximal aggregates were larger and included water upon deposition, whereas distal aggregates were much smaller and more fragile (Fig. 4f). In proximal areas, almost all lapilli particles were coated with fine ash particles (Fig. 4b, c). Lapilli that fell inside buildings were coated with fine ash (Fig. 4e), although these coatings were thinner than those on lapilli falling outside (Fig. 4b-d). This suggests that the lapilli that fell inside buildings were coated with fine ash prior to deposition. AP1 were mostly deposited between 4 and $10 \mathrm{~km}$ from the vent, however, they were identified as far as $24.6 \mathrm{~km}$ away (Additional file 2, site OAZ). Within $20 \mathrm{~km}$ of the vent, AP1 deposited atop the coarse lapilli layer exhibited coalescence (Fig. 4c).

Liquid pellets (AP3) were recognized using tracks of mud-rain deposited on the roofs and walls of structures and on the ground as far as $26.4 \mathrm{~km}$ from the vent (Fig. 4d); their aggregate structures were completely destroyed upon impact. AP3 decreased in diameter with increasing distance from the vent. At site IG $(6.4 \mathrm{~km}$ from vent), AP3 on roofs were $10-14 \mathrm{~mm}$ in diameter while those on the south wall were 5-10 $\mathrm{mm}$ along their short axis and light to pale gray in color when dry. In contrast, AP3 on roofs were $2-7 \mathrm{~mm}$ in diameter at a distance of $26.4 \mathrm{~km}$ from the vent (site ICY).

\section{Internal structure, grain-size, and fraction of ash aggregates Poorly structured accretionary pellets (AP1)}

Accretionary pellets were subspherical or slightly prolate or oblate in shape when observed under the microscope (Fig. 5a), with an average diameter of $2.64 \mathrm{~mm}$ and a density of $1380 \mathrm{~kg} / \mathrm{m}^{3}$ (Additional file 3). AP1 pellets were so strong that they could not be crushed by deposition, sampling, wet-sieving and ultrasonic cleaning. Based on SEM observations, accretionary pellets were poorly structured (i.e., AP1) with massive ash cores and porous rims $0.2-0.6 \mathrm{~mm}$ wide (Fig. $5 \mathrm{~b}$ ). Cores consisted of $<400 \mu \mathrm{m}$ particles and were densely packed with finer particles $(<32 \mu \mathrm{m})$, whereas rims consisted of ash particles $(32-400 \mu \mathrm{m})$ relatively poorer in fines.

\section{Coated particles (PC2)}

Regardless of distance from the vent, unwashed samples of coarse ash and lapilli mostly consisted of core particles coated with finer particles (Additional file 2, Fig. 6a). Most of the finer coating particles were removed by water washing (Fig. 6b).

Unwashed samples of lapilli were separated into core particles and finer coating particles (i.e., $<2 \mathrm{~mm}$ ) by
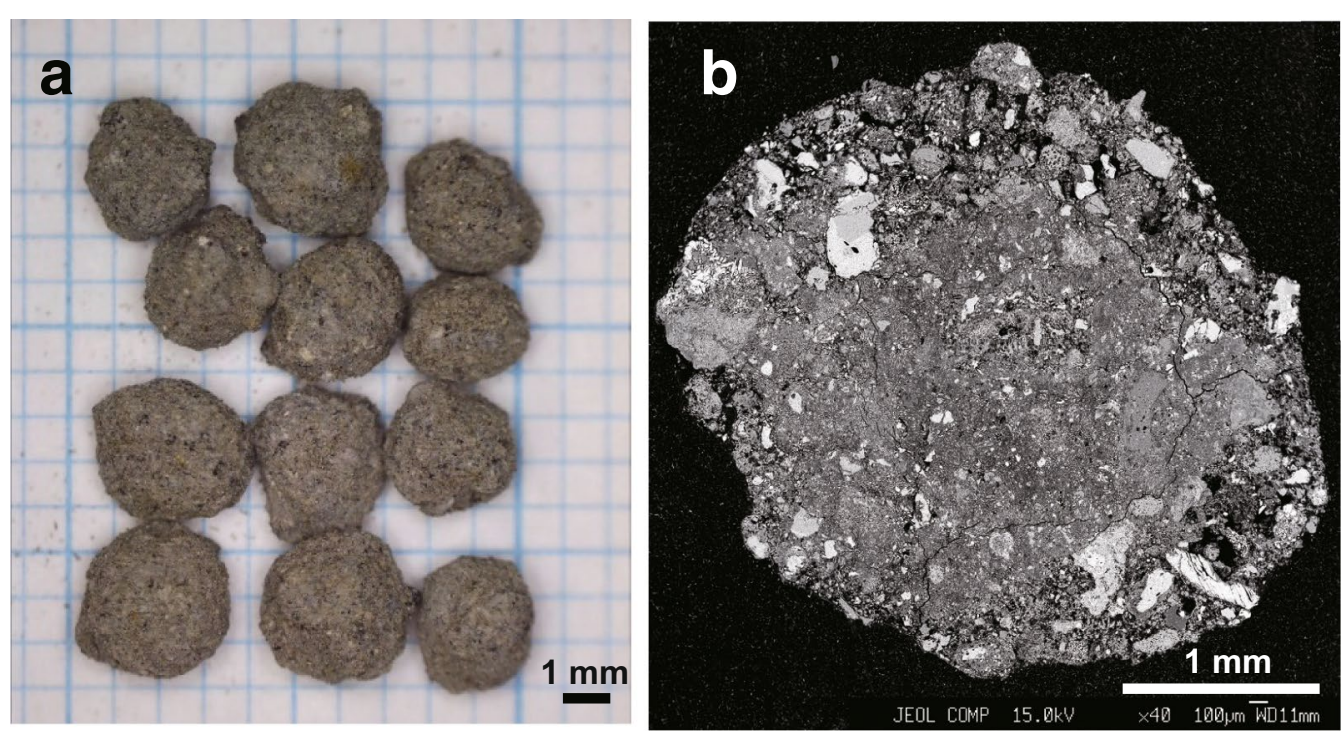

Fig. 5 Examples of accretionary pellets (AP1) at site IG, $6.4 \mathrm{~km}$ from vent. a Photograph of AP1. b SEM micrograph showing the cross section of an AP1 pellet. Scale bars $1 \mathrm{~mm}$ 

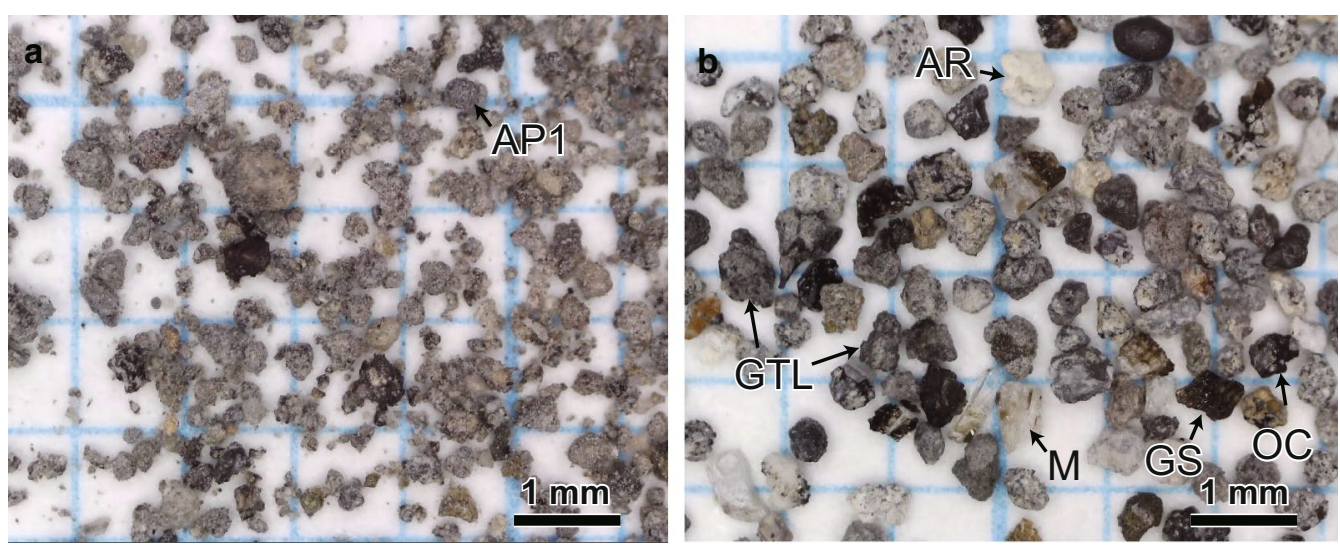

Fig. 6 Comparison of coated particles and core particles after removing their fine ash coating. a Unwashed samples and $\mathbf{b}$ washed samples from site ASP (3.6 km from vent) sieved to 2-3 $\varphi$. The unwashed ash mostly consists of particles coated by finer ash particles. Gridded scales are $1 \mathrm{~mm}$. AP1 accretionary lapilli 1, AR altered rock, GTL gray tuff/lava, GS glass shard, M mineral, OC opaque clast

wet-sieving (Additional file 4). When washed, coating particles finer than $-1 \phi$ accounted for $\sim 3.4 \mathrm{wt} \%$ of the unwashed lapilli sized $8-16 \mathrm{~mm}, 13-14 \mathrm{wt} \%$ of the unwashed lapilli sized $4-8$ and $2-4 \mathrm{~mm}$, and $\sim 75 \%$ of the unwashed very coarse sand-sized ash fraction (1-2 $\mathrm{mm}$ ) (Additional file 4). We noted that, in the 1-2 mm fraction, it was difficult to distinguish between cores and finer coating particles. Particles finer than $5 \phi$ included very fine ash particles and absorbing compounds.

\section{Grain-size variations between sites}

We performed grain-size analyses using dry-sieving and a combination of wet-sieving and laser diffraction analyses. To avoid redundancy, we herein refer to the combination of wet-sieving and laser diffraction analyses as "wetsieving". The dry-sieved results represent the grain-size distributions (GSDs) of particles that fell on the ground, although some particles were broken or disrupted during impact (Bagheri et al. 2016), sampling, and sieving. Since wet-sieving can disrupt aggregated particles, the wetsieved results represent the initial GSDs of tephra within the eruption plume (i.e., before sedimentation, aggregation, and deposition). In 9 of the 15 samples analyzed, coarse- and fine-grained subpopulations were identified, here referred to as SP1 and SP2, respectively.

\section{Dry sieving}

At site ASP, $2 \mathrm{~km} \mathrm{NW}$ of the dispersal axis, the deposit is well-sorted and unimodal with a peak at $2 \phi$ (Fig. 7). In the area of maximum deposition, a very poorly sorted and multimodal deposit was identified (sites ASK, I5, and IG; Fig. 7). With the exception of the most proximal site (ASP; $3.6 \mathrm{~km}$ from vent) and the most distal site (IYM; $257.4 \mathrm{~km}$ ), the deposit is roughly bimodal along its entire dispersal axis (Fig. 7), with a predominant coarser peak and a minor finer peak. The diameter of the coarser peak shifted from $-3 \phi$ to $2 \phi$, and the percentage of the coarser fraction decreased from proximal to distal study areas. In contrast, the finer peak is stable at $4 \phi$ and the percentage of the fine fraction increases with distance from the vent (Fig. 7). At the most distal site (IYM), the deposit is well-sorted and unimodal with a peak at $4 \phi$.

\section{Wet sieving}

Differences between the dry- and wet-sieved GSDs are dominated by the differing fraction of aggregated particles. In all samples, the wet-sieved fine ash fractions were larger than those in the dry-sieved fractions (Fig. 7). Fine ash accounted for only a few percent of the proximal drysieved sample and $22 \mathrm{wt} \%$ of the proximal wet-sieved sample (site IG, $6.4 \mathrm{~km}$ from vent), $10-20 \mathrm{wt} \%$ of the distal dry-sieved sample and $30-33 \mathrm{wt} \%$ of the distal wetsieved sample (sites KND and SGN, 58.4 and $84.4 \mathrm{~km}$, respectively), and $28 \mathrm{wt} \%$ of the dry-sieved sample and 46 $\mathrm{wt} \%$ of the wet-sieved sample at the far distal site (IYM, $257.4 \mathrm{~km}$ ) (Fig. 7). In the sample collected at I5, coalesced coarse particles decomposed during wet-sieving, resulting in a decrease of fragments coarser than $-1 \phi$ wetsieved GSD (Fig. 7).

\section{Grain-size variation with the distance from the vent}

Detailed analyses of individual samples highlight a rapid decay of both the median grain size of dry-sieved samples and the maximum grain size from proximal to distal samples, followed by a less sharp decrease between 50 and $350 \mathrm{~km}$ (Fig. 8a). The fining trend is segmented into three parts by two breaks in the slope at approximately $10 \mathrm{~km}$ and $50 \mathrm{~km}$ (Fig. 8a).The median 


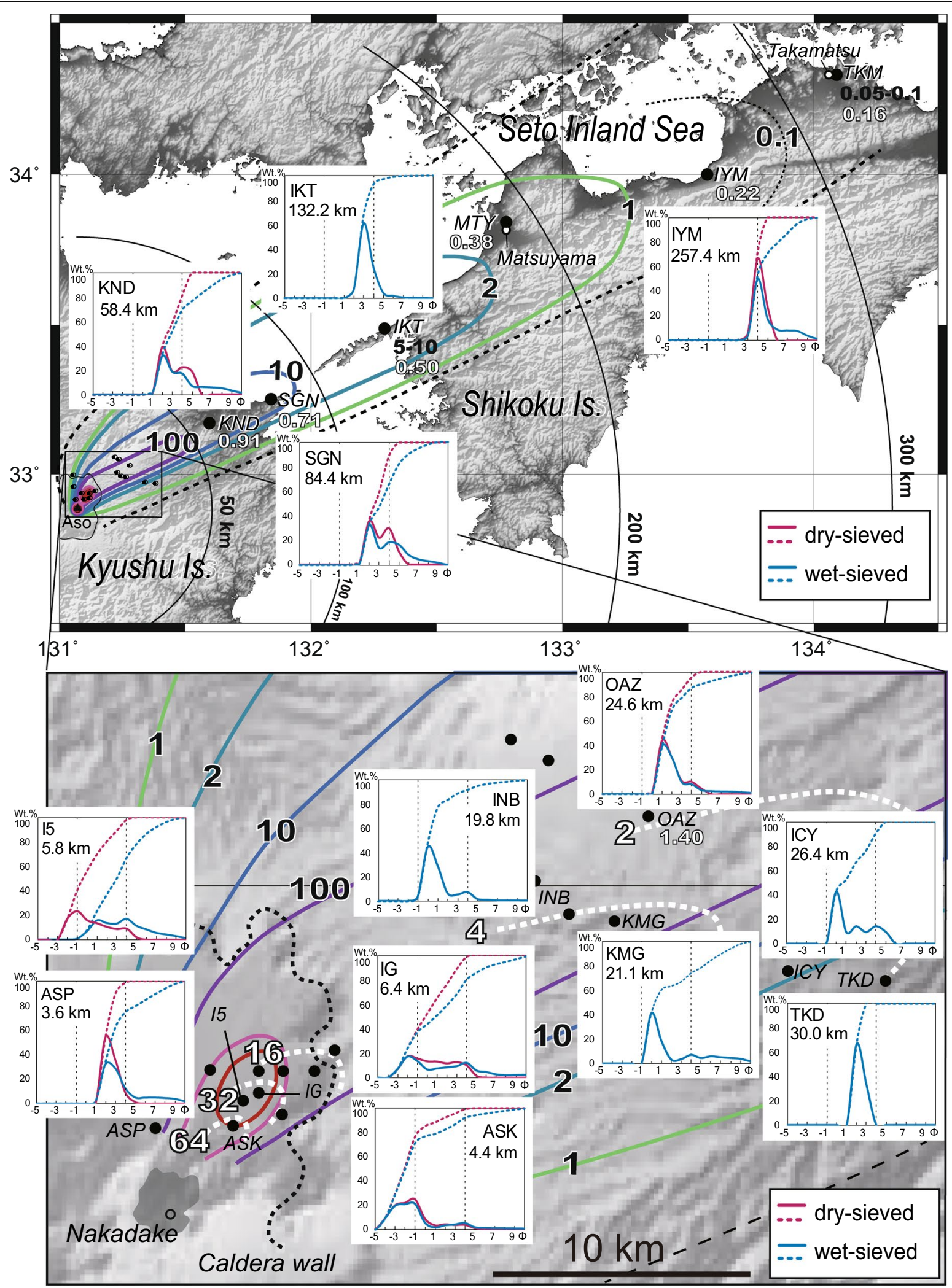

Fig. 7 Grain-size distributions (GSDs, solid lines) and cumulative GSDs (dashed lines) of 13 samples from the 8 October 2016 Aso Nakadake fallout deposit. Dry-sieved (blue curves and dashed lines) and wet-sieved (red curves and dashed lines) samples are indicated. GSDs are plotted on the mass distribution map of Fig. 2. Numbers under the site identifiers indicate distance from the vent $(\mathrm{km})$ 

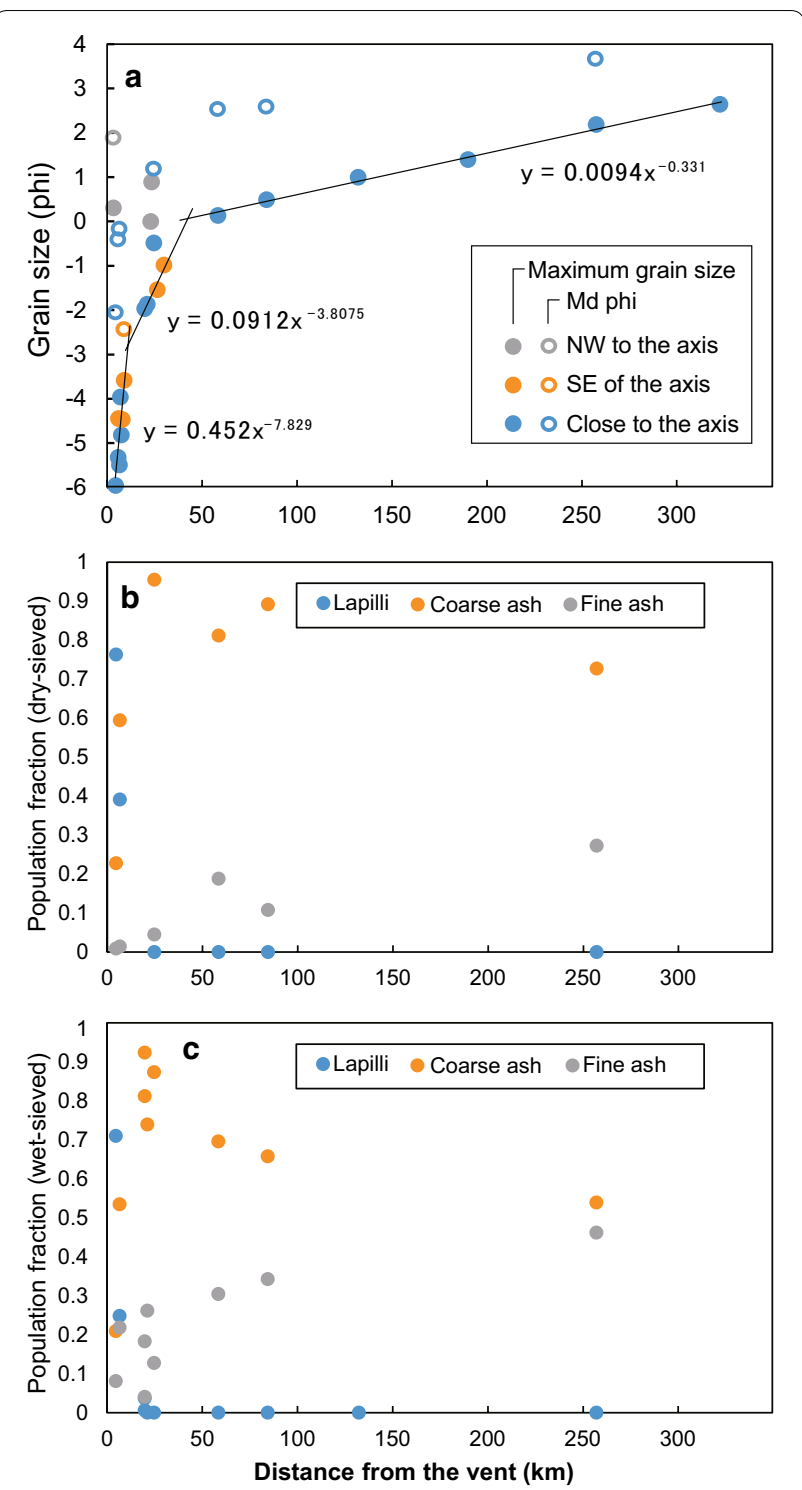

Fig. 8 Variations according to the distance from the vent of a maximum grain size and median diameter by dry-sieving collected from northwest, southeast and along the sedimentary axis; $\mathbf{b}$ fraction of lapilli, coarse ash and fine ash components obtained by dry-sieving and $\mathbf{c}$ by wet-sieving

and maximum grain sizes collected northwest of the sedimentary axis were finer than those collected from the southwest side and close to the axis (Fig. 8a). The population fraction based on dry- and wet-sieving is characterized by a very steep decrease of lapilli clasts within $10 \mathrm{~km}$ of the vent (Fig. 8b, c). The fraction of fine ash is very small in the proximal area but progressively increases in more distal areas as measured by dry-sieving, whereas the fraction at the proximal area measured by wet-sieving is significantly larger (Fig. 8b, c).

\section{TGSD}

The TGSD based on dry-sieved GSDs (TGSD-d) has mean particle size of $-0.5 \phi$ and very poor sorting of $2.3 \phi$, reflecting a bimodal distribution. This population can be separated by three log-normal fittings with coarse (SP1, peak at $-2.5 \phi$ ) and intermediate subpopulations (SP2, peak at $1.2 \phi$ ), together with a smaller fine subpopulation (SP3, peak at 3.7 $\phi$ ) (Fig. 9a). The TGSD based on wet-sieved GSDs (TGSD-w) has a mean particle size of $1.0 \phi$ and very poor sorting of $3.6 \phi$, being trimodal with coarse (SP1, peak at $-2.7 \phi)$, intermediate (SP2, peak at $1.0 \phi)$, and fine subpopulations (SP3, peak at $3.8 \phi$ ) (Fig. 9b). SP1 is the predominant mode in both TGSDs. Although SP2 is secondary and SP3 is minor in TGSD-d, SP3 is wider than SP2 in TGSD-w. SP3 is positively skewed in TGSD-w, including abundant fine ash (4-11 $\phi$ ) compared to TGSD-d, which could be caused by an increase of fractions finer than $2 \phi$ when compared to TGSD-d (Fig. 9c). Indeed, the fine ash fraction is $2.4 \mathrm{wt} \%$ in TGSD-d, increasing to $20.4 \mathrm{wt} \%$ in TGSD-w.

\section{Particle density}

We measured the density of clasts in each size range between -4 and $5 \phi$. clasts larger than $1 \mathrm{~mm}$ were collected from sieved samples at site IG $(6.4 \mathrm{~km})$ and finer particles were collected at sites SGN $(84.4 \mathrm{~km})$ and IKT $(132.2 \mathrm{~km})$. Plotting density versus diameter shows that values range from approximately 1320 to $2750 \mathrm{~kg} / \mathrm{m}^{3}$ (Additional file 5). Density values are high for particles with diameter 3-4 $\phi$ and decrease according to increasing particle diameter following an approximately linear trend (Additional file 5).

\section{Component analysis}

We also performed component analysis of two wetsieved samples (Fig. 10) representative of the proximal (site ASK, $4.4 \mathrm{~km}$ from vent) and medial areas (site OAZ, $24.6 \mathrm{~km}$ ). We classified particles as follows: (1) brown to green-brown colored glass shards of mostly vesicular or non-vesicular glass with vitreous surfaces, where the particle size was less than $1 \mathrm{~mm}$ (glass shards); (2) opaque volcanic rock or glassy clasts with variably crystalized surface, adhering white secondary minerals, and with particle sizes less than $4 \mathrm{~mm}$ (opaque clasts); (3) broken fragments of vesicular lava or solidified tuff with weakly oxidized surfaces onto which ash and lapilli coalesced, exhibiting a wide particle size range below $64 \mathrm{~mm}$ (gray tuff); (4) moderately to highly oxidized and altered particles including holocrystalline, volcanic rock, etc., with a wide range of color including yellow, brown, white, orange, and red, and particle sizes less than $8 \mathrm{~mm}$ 

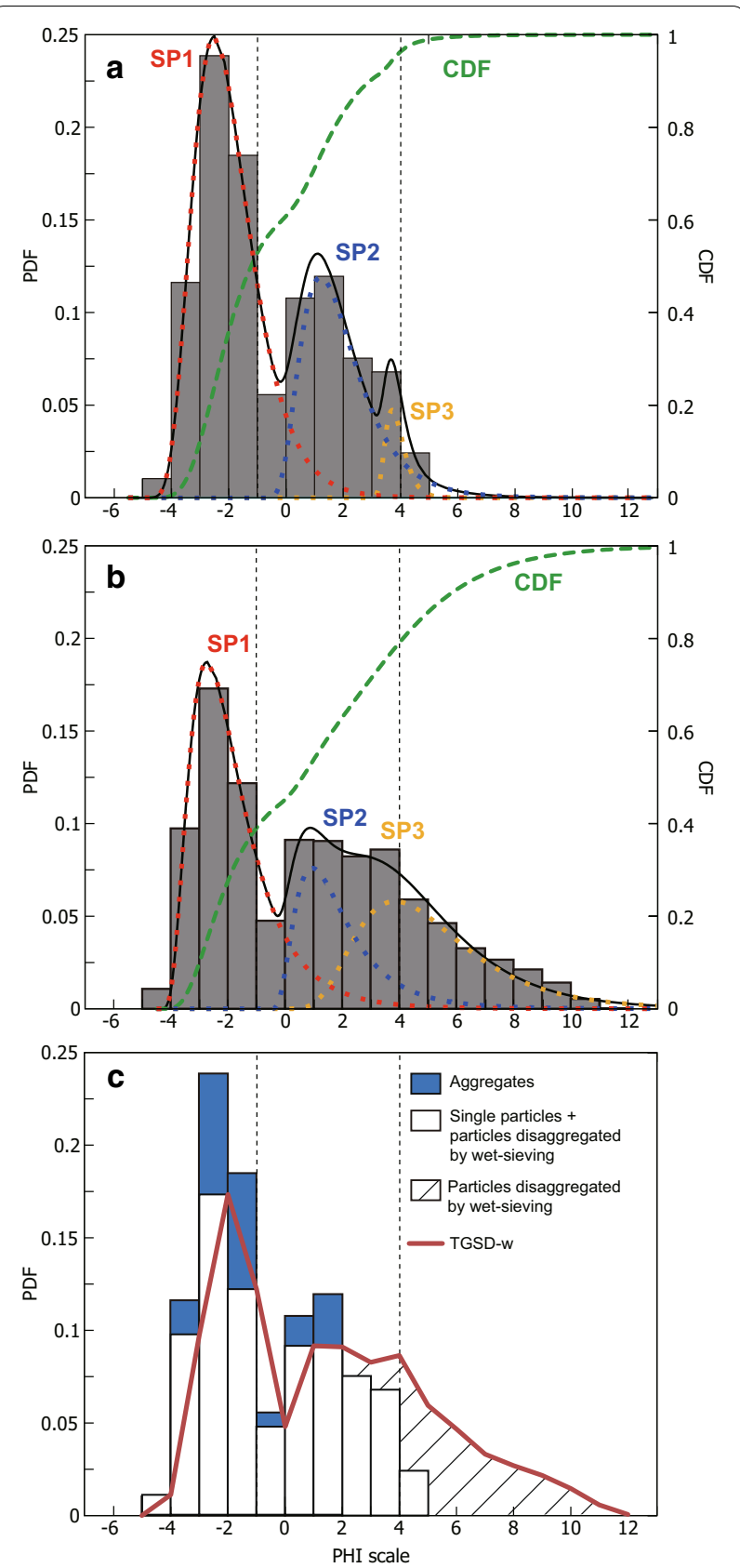

Fig. 9 Total grain-size distributions (TGSDs) based on a dry-sieving and $\mathbf{b}$ combined wet-sieving and laser diffraction analyses. Histograms indicate the probability density function (PDF), green dashed lines the cumulative distribution function (CDF), red dotted lines the coarse subpopulation SP1, blue dotted lines the intermediate subpopulation SP2, and the yellow dotted line the fine subpopulation SP3. c Comparison of TGSD-d and TGSD-w made by overlapping the histograms of Fig. 9a, b shown by red line

(altered rocks); and (5) free minerals or broken fragments of feldspar and orthopyroxene with or without adhering glass, exhibiting particle sizes less than $1 \mathrm{~mm}$ (minerals).
The GSD at site ASK is bimodal, with a predominantly coarse mode peaking around -2 to $-1 \phi$ and a minor finer mode peaking at $2-4 \phi$ (Fig. 10a). The deposit at site ASK comprised $77 \mathrm{wt} \%$ gray tuff, $8.8 \mathrm{wt} \%$ altered rocks, 10.5 $\mathrm{wt} \%$ opaque clasts, $3.5 \mathrm{wt} \%$ fresh glass, and $1.2 \mathrm{wt} \% \mathrm{~min}-$ erals (Fig. 10a). Lapilli were mostly gray tuff ( $95 \mathrm{wt} \%$ ) with small amounts of altered rock and opaque clasts, whereas ash particles consisted of variable fractions of gray tuff/lava, altered rocks, minerals, opaque clasts, and glass shards (Fig. 10a). The GSD at site OAZ, representative of medial areas, is bimodal, with a predominant coarse mode peaking around $1 \phi$ and a minor finer mode peaking at $4 \phi$ (Fig. 10a) and skewed from 0 to $11 \phi$ (Fig. 10b). The components at this site are similar to that of the ash-sized particles at the ASK site (Fig. 10).

\section{Grain size-dependent terminal fall velocity}

The terminal velocity depends on particle properties, such as grain size, shape, and density, on atmospheric density, and also on the altitude at which the plume spreads. To calculate the terminal fall velocities of clasts at the bottom of the eruption plume, we adopted the numerical method of Walker et al. (1971) on the assumption that clasts can be accurately approximated as spherical solid particles. This method accounts for the effects of varying drag coefficients depending on the particle Reynolds number Re. For particles more than several millimeters in diameter, the relationship may be approximated by the terminal fall velocity $v$ at high Re:

$$
v=\sqrt{\frac{4 g D}{3 C_{\mathrm{d}}}\left(\frac{\rho_{\text {clast }}-\rho_{\mathrm{air}}}{\rho_{\mathrm{air}}}\right)},
$$

where $\rho_{\text {air }}$ and $\rho_{\text {clast }}$ are the atmospheric and clast densities, respectively, $g$ is the acceleration due to gravity, $D$ is the clast diameter, and $C_{\mathrm{d}}$ is the drag coefficient, which is on the order of 1 (e.g., Bursik et al. 1992; Sparks et al. 1992; Koyaguchi 1994). In this study, we used $C_{\mathrm{d}}=0.47$ at $R e>1000$ following Koyaguchi (2008). For particles smaller than $10^{2} \mu \mathrm{m}$, this relationship is approximated by Stokes' settling velocity at low $R e$ as follows:

$$
v=\frac{\left(\rho_{\text {clast }}-\rho_{\text {air }}\right) g D^{2}}{18 \mu}
$$

where $\mu$ is the viscosity of air. Finally, for particles between $10^{2} \mu \mathrm{m}$ and several millimeters in diameter, the relationship is approximated by the terminal fall velocity at medial $R e$ :

$$
v=4 g^{2}\left(\frac{4 g^{2}\left(\rho_{\text {clast }}-\rho_{\text {air }}\right)^{2}}{225 \mu \rho_{\text {air }}}\right)^{\frac{1}{3}} D .
$$



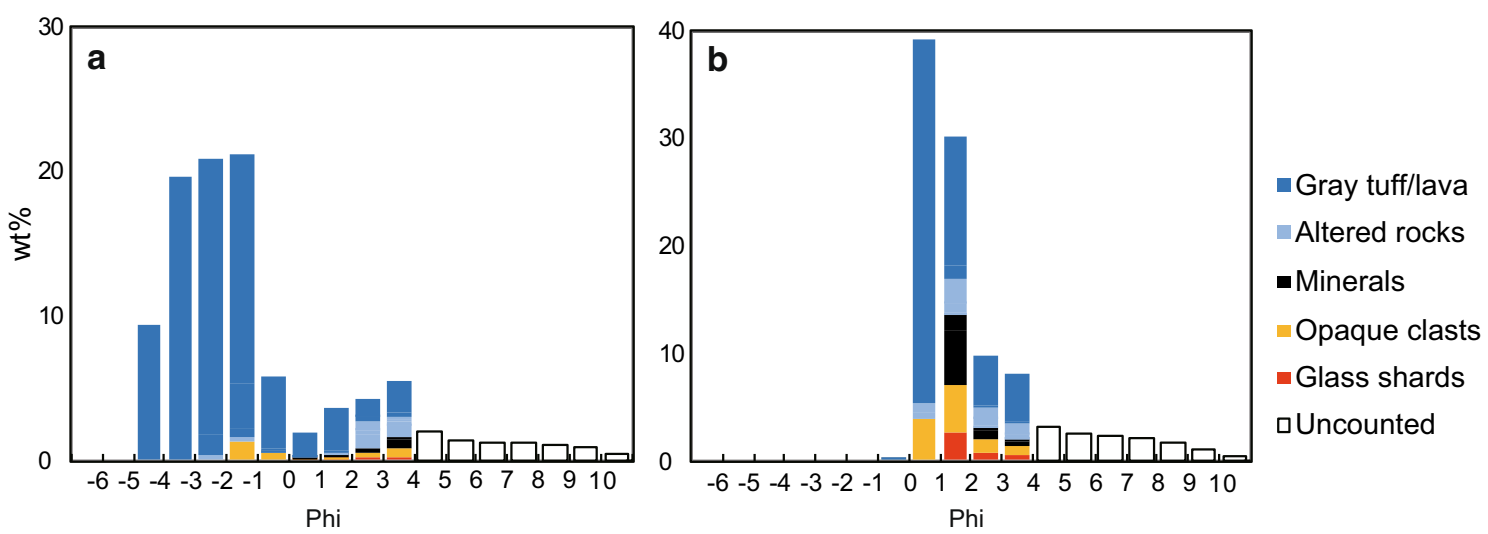

Fig. 10 Componentry classes shown within the GSD histograms at a site ASK, $4.4 \mathrm{~km}$ from the vent and $\mathbf{b}$ site OAZ, $24.6 \mathrm{~km}$ from the vent

The average density of clasts generally varies from 1000 to $3000 \mathrm{~kg} / \mathrm{m}^{3}$ depending on grain size, reflecting the variation of the modal composition with grain size. Atmospheric density varies by one order of magnitude from $\sim 10^{0} \mathrm{~kg} / \mathrm{m}^{3}$ near sea level to $\sim 10^{-1} \mathrm{~kg} / \mathrm{m}^{3}$ at the tropopause (Additional file 6). Since variations in clast and atmospheric density may affect the estimated terminal fall velocities in several ways, these effects must be taken into account. Terminal fall velocities calculated as a function of grain size, clast density, and atmospheric density are shown in Additional file 7.

Due to our limited sample size, particle densities included inherent uncertainties, and we therefore approximated grain densities as a function of grain size using the linear trend shown in Additional file 5 to calculate terminal fall velocities for each grain size (Additional file 7). Our results show that the terminal velocity of grains is affected by the assumed altitude of the bottom of the erupted plume, particularly for grains coarser than $0.25 \mathrm{~mm}(2 \phi$, Fig. 11). Thus, we suggest that the dispersal behavior of particles finer than $2 \phi$ is different from that of lapilli.

\section{Discussion}

\section{Wind-effected tephra deposition}

Our study of tephra transport and deposition from the 2016 Aso eruption has highlighted important aspects of sedimentation processes associated with wet volcanic explosions. The tephra fall was characterized by variable accumulation and grain size features that were possibly related to the primary grain-size distribution in the plume, atmospheric heterogeneities, and particle aggregation. Various aggregation processes enhanced the sedimentation and settling velocities of fine particles.

The tephra-fall deposits show a narrow cross-wind deposition (Fig. 2), the median diameter rapidly decreasing

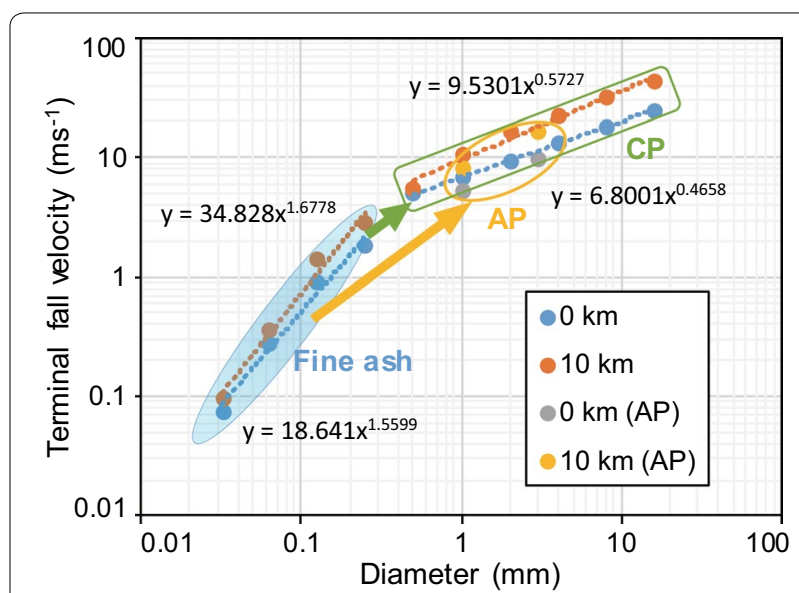

Fig. 11 Grain size-dependent terminal fall velocities of clasts at 0 and $10 \mathrm{~km}$ a.s.l. calculated using the numerical method of Walker et al. (1971). We used the average clast densities as a function of grain size (Additional file 7). Note that fine ash particles constituting accretionary pellets (AP) and aggregate shells of coated particles (CP)

have terminal velocities up to several orders of magnitude greater than their individual fall velocities (yellow arrow). The fall velocities of larger core particles coated by fine ash are only slightly increased (green arrow)

with distance from the vent (Fig. 8). These characteristics are typical of tephra deposits associated with a bent-over plume (Bonadonna et al. 2005). The offset of the proximal deposition from the Aso volcano, e.g., that the region 2-3 km NE of the vent was not covered by the tephra, but $6 \mathrm{~km}$ away there was strong coverage, is similar to the deposition of tephra following the 14 October 1995 Ruapehu eruption; tephra from that eruption was interpreted to have been deposited under a strong wind after forming a high plume (10-12 km; Cronin et al. 2003). The Aso ejecta is also interpreted to have deposited under strong wind from a plume that reached $11.9 \mathrm{~km}$. Winds at lower 
to middle altitudes strongly affected the flow of the plume to the NE (Fig. 3, Additional file 1). The dispersal axis shifted northwestward against the axis of maximum grain size (Fig. 2). Relatively wider distributions and finer maximum grain sizes were noted northwest of the depositional axis compared to the southeast and along the axis (Figs. 2, 8a). This asymmetric distribution is considered to result from advection caused by different wind directions, i.e., from SW-west at middle-to-higher altitudes and from SE-SW at lower and middle altitudes (Additional file 1). Relationships between asymmetric distributions and different wind conditions at each altitude have been reported for other eruptions (e.g., the 2004 Mt. Asama eruption; Yoshimoto et al. 2005, and the 1992 Spurr eruption; Durant and Rose 2009). Within $10 \mathrm{~km}$ of the vent, tephra-fall depositing to the NE side of the vent formed secondary accumulation maxima. Beyond $10 \mathrm{~km}$, however, it deposited in the ENE direction. From these observations, we assume that wind at lower-to-middle altitudes caused the plume to drift to the NE, whereas wind at middle-to-higher altitudes caused it to flow ENE (Figs. 2, 3, Additional file 1; Sato et al. 2018).

\section{Secondary accumulation maxima}

A plume with strong reflectivity was estimated to have formed at $6 \mathrm{~km} \mathrm{NE}$ by 01:58 (Fig. 3b; Weathernews Inc. 2016). The strong reflectivity could be traced up to $8 \mathrm{~km}$ NE from the vent at middle altitudes, but it disappeared beyond $8 \mathrm{~km} \mathrm{NE}$ (Fig. 3b, c). The passage of the strongly reflective plume coincided with the secondary accumulation maxima of tephra (Figs. 2, 3), which also started around 01:58 at approximately $6 \mathrm{~km} \mathrm{NE}$ of the vent. This suggests that tephra forming the secondary accumulation maxima originated from the strongly reflective plume (Fig. 3). The plume at $6 \mathrm{~km} \mathrm{NE}$ was still at lower to middle altitudes, estimated to reach approximately $8 \mathrm{~km}$ a.s.l. at $10 \mathrm{~km}$ ENE from the vent (Fig. 3b), suggesting that the tephra did not fall from the top of the plume but from the lower portion. Furthermore, a large amount of aggregates in the proximal tephra suggest that the plume was rich in water, denoting that the wet aggregation was formed rapidly (approximately $10 \mathrm{~min}$ after the end of the explosive eruption) within the plume. Wet aggregation increases the size and density of tephra particles, facilitating the effective removal of fine ash from the plume (e.g., Brown et al. 2012) to form secondary mass accumulation maxima in proximal areas approximately $4-8 \mathrm{~km}$ from the vent (Fig. 2). In general, secondary accumulation maxima are documented in distal regions, typically hundreds of kilometers from the volcano (e.g., the 1980 eruption of Mt. St. Helens; Sarna-Wojcicki et al. 1981, June 15, 1991 eruption of Pinatubo; Weisner et al. 2003, and the August 18 and September 16-17, 1992 eruptions of Mt Spurr;
McGimsey RG Neal and Riley 2001). Wet aggregation could have enhanced the effective removal of airborne fine particles from the plume. Rapid aggregation within the wet plume and the deposition of abundant fine ash were also recorded in the 2009 Redoubt eruption (Van Eaton et al. 2015).

\section{Wet and dry aggregation}

We observed various types of aggregates (Additional file 2, Figs. 4, 5, 6), the type and size of which varied according to the distance from the vent: proximal aggregates were larger and contained more water upon deposition, whereas distal aggregates were much smaller and more fragile (see "Deposit characteristics" section).

The large amount of AP3 deposited within $30 \mathrm{~km}$ of the vent suggests that abundant water played an important role in aggregation. When water is present, the mixture becomes oversaturated and the aggregates collapse into either structureless slurry or liquid pellets (e.g., Van Eaton et al. 2012) rather than forming individual solid spherical particles such as AP1. Indeed, large volumes of ash and water within plumes are known to produce localized rainfall beneath plumes (Gilbert and Lane 1994), and may also encourage the formation of liquid pellets (AP3). During the 2016 eruption, it was humid at ground level around Mt. Aso (Japan Meteorological Agency 2016), and the crater lake was present. This might explain the volume of water supplied to the plume (Fukuoka Regional VOWC 2016).

AP1 particles were either subspherical or oblate (Fig. 5), suggesting that water (surface tension) was involved in their formation. However, AP1 particles were coalesced by finer particles and could not be disaggregated by deposition, sampling and ultrasonic cleaning. Their strong and stable aggregation is difficult to explain only by adhesion forces from hydrostatic bonding (e.g., Gilbert and Lane 1994) and electrostatic bonding (e.g., Carey and Sigurdsson 1982), such that other mechanisms must have acted to stabilize the aggregates (e.g., salt precipitation, Colombier et al. 2019). During the eruption, a large amount of soluble acidic gas, such as $\mathrm{SO}_{2}$, was observed, and the preceding small eruption on October 7 at the same crater included 15,000 tons of $\mathrm{SO}_{2}$ (Ishii et al. 2016) that has been considered to drive salt precipitation on volcanic ash surfaces (Colombier et al. 2019). Further chemical analyses are needed to understand the mechanics of the aggregation process, including whether salt precipitation played a role in the coalescence of the aggregates (Colombier et al. 2019). Witness observations suggest that deposits including lapilli and AP1 and AP3 particles at locality IG were deposited under dry conditions and yet coalesced with each other (Fig. 4c). This 
suggests the dry-up of a liquid phase subsequent to the deposition of AP3 caused salt precipitation and promoted the coalescence of particles.

Small amounts of ash clusters (PC1) and coated particles (PC2) were ubiquitous within $260 \mathrm{~km}$ from the vent (Figs. 7, 8). Microscopic observation of particle clusters suggests that they comprise loosely bound, irregular morphologies. They are fragile and disaggregate during water washing (Fig. 6). Relatively dry conditions can give dry aggregations such as loosely bound particle clusters characterized by low density and irregular morphologies (Sorem 1982). Moisture, electrostatic bonds, or mechanical interlocking may also play a role in the formation of such dry aggregates (Carey and Sigurdsson 1982). Fine particle aggregation is thus important in the settling of ash from eruption clouds (e.g., Taddeucci et al. 2011; Brown et al. 2012).

\section{Effect of aggregation on ash sedimentation}

The eruption plume with a maximum height of $11.9 \mathrm{~km}$ a.s.l. (JMA 2016; Tokyo Volcanic Ash Advisory Center 2016; Sato et al. 2018) was strongly affected by westerly winds (Fig. 3, Additional file 1) and drifted more than $300 \mathrm{~km}$ ENE. Tephra deposition started at 01:58 JST in proximal areas and at 04:39 JST at site IKT $(132.2 \mathrm{~km}$ from vent); the duration of sedimentation was approximately five minutes at the site. Based on our calculated terminal velocities for particles of different sizes (Fig. 11, Additional file 7), the terminal fall velocity of $4 \phi$ particles is $0.3 \mathrm{~m} / \mathrm{s}$ at sea level and $0.4 \mathrm{~m} / \mathrm{s}$ at $10 \mathrm{~km}$ a.s.l. Assuming that the particles fell at a constant velocity from the eruption plume at $10 \mathrm{~km}$ a.s.l., such fine ash particles should have settling times around 6.9-9.3 h, which is inconsistent with the observed deposition time. This result suggests that particles finer than $4 \phi$ were not deposited as individual particles, but instead settled as aggregates.

Aggregated fine ash particles have terminal velocities up to several orders of magnitude greater than their individual fall velocities, which likely prompted the early sedimentation of AP1 in proximal areas (Figs. 8c, 11). Bagheri et al. (2016) reported that the aggregation of fine particles also delayed sedimentation via the rafting of aggregate particles. The plot of maximum grain size versus distance from the vent shows a gentle slope beyond $50 \mathrm{~km}$ from the vent, suggesting distal ashfall advection by the wind, while rafted large particles were not observed (Fig. 8a). The aggregated fine ash shells of coarse lapilli-sized cored clusters comprised $~ 3.5 \mathrm{wt} \%$ of the aggregated particles (Additional file 4), which is too little to significantly affect the terminal velocity of the larger core particles.
Grain-size bimodality in individual samples

Most grain-size distributions based on both sieving methods along the dispersal axis were multimodal. The coarser mode in dry samples progressively decreased in grain size with distance from the vent, whereas the finer mode was evenly distributed around $4 \phi$ regardless of distance from the vent (Fig. 7). The regular fining of the coarse mode suggests normal settling of individual clasts as dictated by the released altitude and wind advection of particles, which also explains the significant decrease in maximum grain size with distance from the vent within $10 \mathrm{~km}$ (Fig. 8a). The fine mode shows evidence of settling dominated by size-selective sedimentation processes (e.g., particle aggregation and/or convective instability; Bonadonna et al. 2015b). We conclude that particle aggregation is the key sedimentation process based on the ubiquitous distribution of aggregates (Fig. 8c). The medial segment of the slope of maximum grain size is considered to reflect the mixing of both the proximal and distal trends.

\section{TGSDs of aggregate-bearing deposits and particles before aggregation}

This portion of the study conducts a comparison between size distributions, representing the aggregate-bearing deposit on the ground (TGSD-d) and particles before aggregation in the plume (TGSD-w) following the 2016 phreatomagmatic eruption of Aso volcano.

TGSD-d is bimodal and could be separated into coarse (SP1, peak at $-2.5 \phi)$ intermediate (SP2, peak at $1.2 \phi)$, and small subpopulations (SP3, peak at 3.7 $\phi$ ). SP1 and SP2 are considered to be related to the components of the deposit. Lapilli-sized particles mostly consisted of gray tuff/lava, whereas ash-sized particles consisted of more varied components, including gray tuff/lava, altered rocks, glass shards and minerals (Fig. 10a). Nakadake released meter-scale bombs of gray tuff/ vesicular lava that had previously composed the crater wall (February 26-28, 1933 eruption; Aoki et al. 1940). The lapilli of gray tuff/vesicular lava and meterscale bombs around the eruption crater on October 8, 2016 (JMA 2016; Miyabuchi et al. 2017) are thought to originate from a part of the crater wall, conduit or their collapsed material. Fragments of altered rocks are considered to have been oxidized at and around the crater bottom as previously suggested by Watanabe (1991). Glass shards and minerals adhered by glass originate from magma. The maximum sizes of altered rock, glass shards and minerals were consistent with the upper limit of the SP2 mode (Figs. 9, 10a). Thus, we interpret the two peaks in TGSD-d to represent the mixing of two grain-size populations of different origins: the 
coarse subpopulation originating from the crater wall rock, conduit or collapsed material, and the fine subpopulation originating from a mixture of fragmented magma and altered material at and around the bottom of the crater. The bimodal subpopulations of TGSD-d could be affected by the breakage of lapilli and disaggregation of particle clusters upon their impacting the ground. The finest subpopulation, SP3, which clearly appears in TGSD-w, is due to the disaggregation of a large amount of aggregates in TGSD-d, however, since AP1 particles were not disaggregated by wet-sieving, AP3, PC1 and PC2 together efficiently resulted in a trimodal grain-size distribution in TGSD-w (Fig. 9b, c). TGSD-w included $20.4 \mathrm{wt} \%$ fine ash compared to only $2.4 \mathrm{wt} \%$ fine ash in TGSD-d, suggesting that aggregated fine particles represented $18 \mathrm{wt} \%$ of the deposit (Fig. 9). These findings contribute to understanding the influence of aggregation on tephra dispersal processes and have implications for tephra-fall hazard assessment.

The TGSD- $\mathrm{d}$ and - $\mathrm{w}$ of Aso volcano may be compared to those of other eruptions that have been similarly sampled. Although the aggregate-bearing TGSD of the 2009 Redoubt E5 eruption was calculated by a different method (Van Eaton et al. 2015), it is also shown for comparison (Fig. 12). TGSD after aggregation of the 2016 Aso eruption shows similar Mdphi and sorting to that of the andesitic sub-Plinian 1996 eruption of Ruapehu (Bonadonna and Houghton 2005). Aso TGSD-d are poorly sorted compared to those of both the 1974 Fuego eruption (Rose et al. 2008) and the aggregate-bearing TGSD of the 2009 Redoubt eruption (Van Eaton et al. 2015). TGSD-w indicates that the disaggregate GSD of the particles of the 2016 Aso eruption are extremely poorly

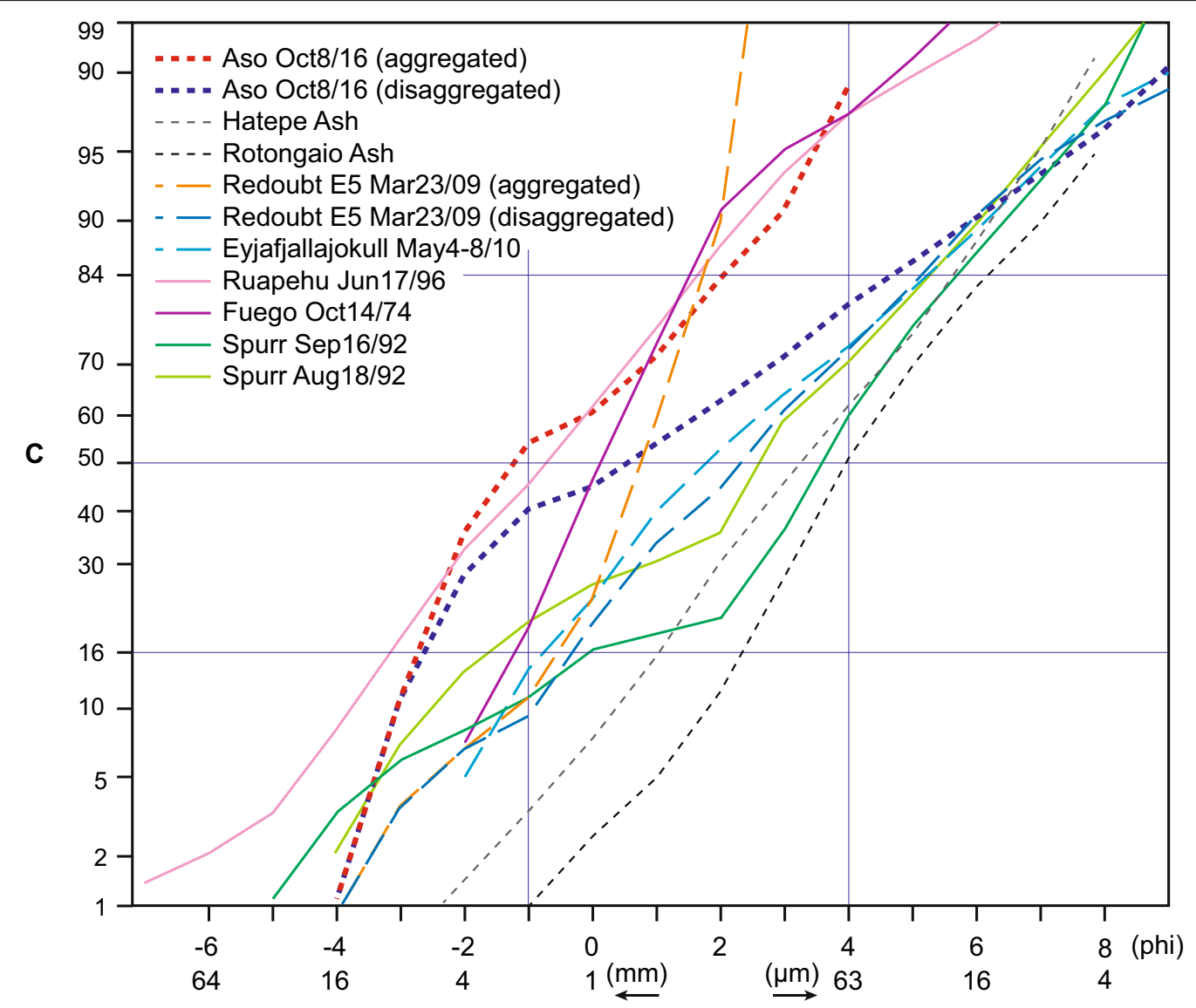

Fig. 12 Comparison of the 2016 Aso eruption total grain-size distributions based on grain-size analyses of dry-and wet-sieving for samples, assessing the size distribution of the primary aggregate-bearing deposits and that of disaggregated deposits. Other air-fall deposits of mafic eruptions based on ground-based sampling are also shown: Hatepe and Rotongaio ashes (Walker 1981); Ruapehu (Bonadonna and Houghton 2005); Fuego (Rose et al. 2008); August 18 and September 16, 1992 Spurr (Durant and Rose 2009); Eyjafjallajökull (Bonadonna et al. 2011); Redoubt (Mastin et al. 2013). Air-fall deposits based on the grain-size analyses and calculation of Van Eaton et al. (2015) are also shown. Note the deference between the size distributions of the primary aggregate-bearing deposits and those of disaggregated deposits. Solid lines denote phreatomagmatic deposits, dashed lines are phreatomagmatic/magmatic deposits, and dotted lines are subplinian/plinian deposits. C=weight percentage coarser than given grain size 
sorted compared to other recent mafic eruptions listed in Fig. 12. The percentage of particles finer than $4 \phi$ is similar to that of the 2009 Redoubt E5 eruption (Mastin et al. 2013) and 2010 Eyjafjallajökull eruption (Bonadonna et al. 2011). This poor sorting could have been caused by certain features of phreatomagmatic eruptions. Firstly, a large fraction of coarse-grained ejecta originating from the vent area (Fig. 10) was released by a strong phreatomagmatic explosion. Our TGSD-d did not include samples from the near-vent area, therefore the actual sorting could have been poorer if it had included these deposits. Furthermore, a large fraction of fine ash was formed by fragmentation following the strong explosion. Finally, the water supply present at the time of the eruption enhanced the removal of fine ash from the plume to be deposited on the ground, making it easier to collect fine ash by ground-based sampling compared to dry eruptions. Considering the supply of water and volcanic acid salts to the plume, an external source of water, such as the crater lake, could have played an important role in the formation of poorly sorted TGSD.

\section{Conclusions}

The tephra-fall deposit associated with the 2016 phreatomagmatic eruption at Aso volcano was studied between 4 and $320 \mathrm{~km}$ from the vent in order to characterize the deposit's stratigraphy, distribution, aggregation and grain size.

1. The dispersal axis shifted northwestward against the axis of maximum grain size. A relatively wide distribution and small maximum grain sizes were found at the northwest of the depositional axis. This asymmetric distribution is explained as resulting from the advection of particles by different wind directions from the southwest in the lower troposphere and the west in the middle troposphere. Tephra-fall deposited to the NE within $10 \mathrm{~km}$ of the vent, but shifted to the ENE beyond $10 \mathrm{~km}$ from the vent. This could have been caused by the plume, which drifted to the NE in the lower troposphere and the ENE in the middle troposphere (Sato et al. 2018).

2. The secondary accumulation maxima at $4-8 \mathrm{~km} \mathrm{NE}$ of the vent is characterized by the deposition of lapilli followed by abundant accretionary pellets (poorly structured pellets, AP1, and liquid pellets, AP3) over a short duration. These particles resulted from aggregation in the wet plume, enhancing the removal of ash from the plume to form the secondary mass maxima at a short distance from the vent.

3. The plume produced various types of aggregates. Poorly structured pellets (AP1) coalesced to become strong and stable. Coalesced aggregates were pos- sibly related to salt precipitation processes. The crater lake is considered to be major source of water and volcanic salt supply to the plume. Abundant water supplied in the cloud caused the formation of liquid pellets (AP3) by hydrostatic attraction. Following deposition, the drying of the liquid phase of AP3 caused salt precipitation. A small amount of ash clusters (PC1) and coated particles (PC2) were ubiquitous within $260 \mathrm{~km}$ of the vent. PC1 and PC2 are considered dry aggregates, and were probably related to hydrostatic attraction, electrostatic bonding or mechanical interlocking.

4. The dry aggregates fell ubiquitously in medial to distal regions. Based on observed grain size, deposition duration, and the calculation of fall velocity, it is estimated that particles finer than $4 \phi$ settled not as individual particles, but as aggregates at terminal velocities increased by up to several orders of magnitude.

5. Most grain-size distributions along the dispersal axis based on both sieving methods were multimodal, with the coarser mode fining according to distance from the vent and the finer mode stabilizing around $4 \phi$, which is interpreted as the mixture of different origins of grain-size distributions. The regular fining of the coarse mode suggests normal settling of individual clasts as dictated by the particle's release height and wind advection, whereas the fine mode is considered to be evidence of settling dominated by size-selective sedimentation processes, such as particle aggregation.

6. This study presents a rare chance to compare the size distribution of aggregate-bearing deposits on the ground (TGSD-d) with particles before aggregation in the plume (TGSD-w) of a phreatomagmatic eruption. The bimodal subpopulations of TGSD-d were affected by the breakage of lapilli and disaggregation of particle clusters when they impacted the ground. The slightly trimodal distributions of TGSD-w represent the mixing of two grain-size populations of different origins: the coarse subpopulation originated from wall rock of the crater, conduit or collapsed material, whereas the fine subpopulation originated from mixture of fragmented magma and altered material at and around the bottom of the crater. Most of the fine subpopulation appeared in TGSD-w due to the disaggregation of fine particles, which were aggregated in TGSD-d. TGSD-w included $20.4 \mathrm{wt} \%$ fine ash compared to only $2.4 \mathrm{wt} \%$ fine ash in TGSD$\mathrm{d}$, suggesting that aggregated fine ash accounted for 18 wt\% of TGSD-d. These findings contribute to understanding the influence of aggregation on tephra dispersal processes and to assess tephra-fall hazards. TGSD-w is extremely poorly sorted compared to 
other recent mafic eruptions. This could be related to features unique to phreatomagmatic eruptions: (1) the release of coarse-grained ejecta originating from the host rock of the crater; (2) the fine particles due to the fragmentation from a phreatomagmatic eruption; and (3) the supply of water and salt from the crater to the plume and aggregation enhancing fine ash on the ground.

\section{Supplementary information}

Supplementary information accompanies this paper at https://doi. org/10.1186/s40623-020-01233-y.

Additional file 1. Height profile of (a) velocity and (b) direction of upper wind at the Fukuoka region meteorological station.

Additional file 2. Summary of collection and deposit characteristics of all samples and sites analyzed. Sample locations are shown in Fig. 2. Accretionary pellets and particle clusters are labeled according to Brown et al. (2012): AP1, poorly structured pellets; AP2, pellets with concentric structures; AP3, liquid pellets; PC, particle clusters (ash clusters and coated particles). N.D. indicates no data; '+ 'in the list of 'Sample for TGSD' indicates that the samples were collected for grain size analyses; ' + ' in the list of 'Types of fallen particles' indicates the presence of particles, and fine ash refers to particles finer than $4 \varphi$

Additional file 3. Average diameter, dry weight, volume, and density of 10 grains of AP1 pellets

Additional file 4. Dry weight and fraction of unwashed and washed lapilli and coarse ash samples (1-16 mm in diameter) obtained from locality IG. The dry weight of the washed sample is shown as that of the core particles (coarser than $-1 \varphi$ ), fine particles $(5$ to $-1 \varphi$ ), and the finest particles (finer than $5 \varphi$ ). Weight fractions were calculated with the dry weight of the unwashed sample as $100 \%$. Values with asterisks indicate the weight and fraction of coating particles with sizes of $0.032-1 \mathrm{~mm}(5-0 \varphi)$.

Additional file 5. Average particle density per size fraction. Samples $6.4 \mathrm{~km}$ (site IG), $84.4 \mathrm{~km}$ (site SGN), and $132.2 \mathrm{~km}$ (site IKT) from the vent were analyzed using a water-filled cylinder. See text for "Methods" section.

Additional file 6. Typical density and viscosity of atmospheric air at 0 and $10 \mathrm{~km}$ a.s.l. in mid-latitude regions. Values at $0 \mathrm{~km}$ a.s.l. and at $10 \mathrm{~km}$ a.s.l. are from U.S. Standard Atmosphere (NOAA, NASA and US Air Force (1976))

Additional file 7. Particle density and terminal fall velocity as a function of grain size. Grain densities were calculated from the linear trend in Additional file 5 .

\section{Abbreviations}

AP: Accretionary pellet; BSE: Backscattered electron; CDF: Cumulative distribution function; GSD: Grain-size distribution; GVP: Global Volcanism Program; JMA: Japan Meteorological Agency; PC: Particle cluster; PDF: Probability density function; SEM: Scanning electron microscope; TGSD: Total grain-size distribution; VOWC: Volcanic Observation Warning Center; VSJ: Volcanological Society of Japan.

\section{Acknowledgements}

We thank the Aso Seishounen Koryu-no-ie and N. Fujimura for permitting our field survey within the facility. T. Kobayashi assisted in the field survey and provided useful discussions. M. Ikeda provided useful suggestions and discussions throughout this study. H. Takano, T. Nagata and T. Yamane provided tephra samples and photographs of the localities. H. Sugawara and N. Kodama provided information on the ash deposited at Matsuyama city and the time of the eruption, respectively. Weathernews Inc. granted permission for us to use information on the trial operation of WITH radar observation image. $\mathrm{H}$. Okada and C. Nakamura helped analyze samples. F. Suzuki produced some of the figures. The authors would like to thank Enago (https://www.enago.jp) for the English language review. The authors thank two anonymous reviewers for thoughtful and constructive reviews that improved the manuscript and T. Yamamoto for editorial assistance. Some figures were prepared with Generic Mapping Tools (Wessel and Smith 1998).

\section{Authors' contributions}

TT, NN, and KO performed the field survey on Kyushu and Shikoku islands. TT analyzed the samples and data in the laboratory and wrote the manuscript. All authors read and approved the final manuscript.

\section{Funding}

No funding was received for this work.

\section{Availability of data and materials}

Please contact the corresponding author for data requests.

\section{Competing interests}

The authors declare that they have no competing interests.

\section{Author details}

${ }^{1}$ Graduate School of Sciences and Technology for Innovation, Yamaguchi University, 1677-1 Yoshida, Yamaguchi City, Yamaguchi 753-8512, Japan. ${ }^{2}$ Shikoku Electric Power Co. Ltd, 2-5, Marunouchi, Takamatsu, Kagawa 760-8573, Japan.

Received: 27 February 2020 Accepted: 9 July 2020

Published online: 16 July 2020

\section{References}

Aoki S, Honda T, Hayamizu I (1940) Report on the activity of Aso volcano, February 1933. Kenshinjihou 11:135-163 https://www.jma.go.jp/jma/kishou/ books/kenshin/vol11p133.pdf (in Japanese)

Bagheri G, Rossi E, Biass S, Bonadonna C (2016) Timing and nature of volcanic particle clusters based on field and numerical investigations. J Volcanol Geotherm Res 327:520-530

Biass S, Bonadonna C (2014) TOTGS: Total grain-size distribution of tephra fallout https://vhub.org/resources/3297 Accessed 26 Jan 2015

Bonadonna C, Houghton BF (2005) Total grainsize distribution and volume of tephra-fall deposits. Bull Volcanol 67:441-456

Bonadonna C, Phillips JC, Houghton BF (2005) Modeling tephra sedimentation from a Ruapehu weak plume eruption. J Geophys Res 110:B08029. https $\cdot / /$ doi.org/10.1029/2004JB003515

Bonadonna C, Genco R, Gouhier M, Pistolesi M, Cioni R, Alfano F, Hoskuldsson A, Ripepe M (2011) Tephra sedimentation during the 2010 Eyjafjallajökull eruption (Iceland) from deposit, radar, and satellite observations. J Geophys Res 116:B12202. https://doi.org/10.1029/2011JB008462

Bonadonna C, Biass S, Costa A (2015a) Physical characterization of explosive volcanic eruptions based on tephra deposits: propagation of uncertainties and sensitivity analysis. J Volcanol Geotherm Res 296:80-100. https:// doi.org/10.1016/j.jvolgeores.2015.03.009

Bonadonna C, Cioni R, Pistolesi M, Elissondo M, Baumann V (2015b) Sedimentation of long-lasting wind-affected volcanic plumes: the example of the 2011 rhyolitic Cordón Caulle eruption, Chile. Bull Volcanol 77:3. https:// doi.org/10.1007/s00445-015-0900-8

Borselli L, Sarocchi D (2004) DECOLOG. https://www.lorenzo-borselli.eu/decol og/ Accessed 26 Oct 2018

Brown RJ, Bonadonna C, Durant AJ (2012) A review of volcanic ash aggregation. J Phys Chem Earth 45-46:65-78

Bursik MI, Sparks RSJ, Gilbert JS, Carey SN (1992) Sedimentation of tephra by volcanic plumes, I, Theory and its comparison with a study of the Fogo A Plinian deposit, Sao Miguel (Azores). Bull Volcanol 54:329-344

Carey SN, Sigurdsson H (1982) Influence of particle aggregation on deposition of distal tephra from the May 181980 eruption of Mount St. Helens volcano. J Geophys Res 87:7061-7072

Cas RAF, Wright JV (1987) Volcanic successions, modern and ancient. Allen and Unwin, London, p 528

Casadevall TJ (1994) The 1989-1990 eruption of Redoubt volcano, Alaska: impacts on aircraft operations. J Volcanol Geotherm Res 62:301-316 
Cashman K, Rust A (2016) Observations of ash on the ground. In: Mackie S et al (eds) Volcanic ash: hazard observation. Elsevier, Amsterdam, pp 25-88

Colombier M, Mueller SB, Kueppers U, Scheu B, Delmelle P, Cimarelli C, Cronin SJ, Brown RJ, Tost R, Dingwell DB (2019) Diversity of soluble salt concentrations on volcanic ash aggregates from a variety of eruption types and deposits. Bull Volcanol 81:39

Costa A, Pioli L, Bonadonna C (2016) Assessing tephra total grain-size distribution: insights from field data analysis. Earth Planet Sci Lett 443:90-107

Cronin SJ, Neal VE, Lecoin tre JA, Hedley MJ, Loganathan P (2003) Environmental hazards of fluoride in volcanic ash: a case study from Ruapehu volcano, New Zealand. J Volcanol Geotherm Res 121:271-291

Durant AJ, Rose WI (2009) Sedimentological constraints on hydrometeorenhanced particle deposition: 1992 Eruption of Crater Peak, Alaska. J Volcanol Geotherm Res 186:40-59

Eychenne J, Le Pennec JL (2012) Sigmoidal particle density distribution in a subplinian scoria fall deposit. Bull Volcanol 74:2243-2249. https://doi. org/10.1007/s00445-012-0671-4

Fukuoka Regional Volcanic Observation and Warning Center (2016) Volcanic activity before and after the explosive eruption of Asosan on October 8, 2016. Report of Coordinating Committee for Prediction of Volcanic Eruption 126:144-174 https://www.data.jma.go.jp/svd/vois/data/tokyo/ STOCK/kaisetsu/CCPVE/Report/126/kaiho_126 25.pdf (in Japanese)

Gilbert JS, Lane SJ (1994) The origin of accretionary lapilli. Bull Volcanol 56:398-441

Global Volcanism Program (2013) Asosan. in Volcanoes of the World, v. 4.7.4. Venzke E (ed.) Smithsonian Institution https://volcano.si.edu/ volcano.cfm?vn=282110. https://doi.org/10.5479/si.GVP.VOTW4-2013. Accessed 29 Oct 2018

Inman DL (1952) Measures for describing the size distribution of sediments. J Sed Pet 22:125-145

Ishii K, Hayashi Y, Shimbori T (2018) Using Himawari-8, estimation of $\mathrm{SO}_{2}$ cloud altitude at Aso volcano eruption, on October 8. Earth Planets Space 70:19. https://doi.org/10.1186/s40623-018-0793-9

Japan Meteorological Agency (2016) Monthly Volcanic Activity Report (October 2016). http://www.data.jma.go.jp/svd/vois/data/tokyo/eng/volca no_activity/2016/2016_10_monthly.pdf

Japan Meteorological Agency (2019) JMA home. https://www.jma.go.jp/jma/. Accessed 30 Mar 2019

Japan Meteorological Agency and Volcanological Society of Japan (2013) National catalogue of the active volcanoes in Japan. http://www.data. jma.go.jp/svd/vois/data/tokyo/STOCK/souran_eng/menu.htm. Accessed 29 Oct 2018

Kawakatsu H, Kaneshima S, Matsubayashi H, Ohminato T, Sudo Y, Tsutsui T. Uhira K, Yamasato H, Ito H, Legrand D (2000) Aso94: Aso seismic observation with broadband instruments. J Volcanol Geotherm Res 101(1-2):129-154

Koyaguchi T (1994) Grain-size variation of the tephra derived from volcanic umbrella clouds. Bull Volcanol 56:1-9

Koyaguchi T (2008) Modelling of volcanic phenomena. University of Tokyo Press, Meguro City (in Japanese)

Lane SJ, Gilbert JS, Hilton M (1993) The aerodynamic behaviour of volcanic aggregates. Bull Volcanol 55:481-488

Mastin LG, Schwaiger H, Schneider DS, Wallace KL, Schaefer J, Denlinger RP (2013) Injection, transport, and deposition of tephra during event 5 at Redoubt Volcano. JVolcanol Geotherm Res 259:201-213

McGimsey RG Neal CA, Riley CM (2001) Areal Distribution, Thickness, Mass, Volume, and Grain Size of Tephra-Fall Deposits from the 1992 Eruptions of Crater Peak Vent, Mt. Spurr Volcano, Alaska) U.S. Geological Survey OpenFile Report 01-370

Miyabuchi Y, Maeno F, Nakada S, Nagai M, lizuka Y, Hoshizumi H, Tanaka A, Itoh J, Kawanabe Y, Oishi M, Yokoo A, Ohkura T (2017) The October 7-8, 2016 eruptions of Nakadake crater, Aso volcano, Japan and their deposits. Abstracts of Japan Geoscience Union-American Geoscience Union Joint Meeting 2017 SVC47-11. https://confit.atlas.jp/guide/event-img/jpgua gu2017/SVC47-11/public/pdf?type=in. Accessed 27 Mar 2018

Murrow PJ, Rose WI, Self S (1980) Determination of the total grain-size distribution in a Vulcanian eruption column, and its implications to stratospheric aerosol perturbation. Geophys Res Lett 7:893-896

NOAA, NASA and US Air Force (1976) U.S. Standard Atmosphere, 1976. http:// www.pdas.com/atmosTable2SI.html. Accessed 31 Oct 2018
Ono K, Watanabe K (1985) Geological map of Aso volcano (1:50,000). Geological map of volcanoes 4, Geological Survey of Japan (in Japanese with English abstract)

Ono K, Watanabe K, Hoshizumi H, Ikebe S (1995) Ash eruption of the Nakadake crater, Aso volcano, southwestern Japan. J Volcanol Geotherm Res 66:137-148

Rose WI, Self S, Murrow PJ, Bonadonna C, Durant AJ, Ernst GGJ (2008) Nature and significance of small volume fall deposits at composite volcanoes: insights from the October 14, 1974 Fuego eruption, Guatemala. Bull Volcanol 70:1043-1067

Sarna-Wojcicki AM, Shipley S, Waitt Jr B (1981) Areal distribution, thickness, mass, volume, and grain size of air-fall ash from the six major eruptions of 1980. In

Sato E, Fukui K, Shimbori T (2018) Aso volcano eruption on October 8, 2016, observed by weather radars. Earth Planets Space 70:105. https://doi. org/10.1186/s40623-018-0879-4

Shimbori T (2017) Volcanic ash and lapilli blowing in the wind. Wind Eng JAWE 42:261-272. https://doi.org/10.5359/jawe.42.261 (in Japanese)

Sorem RK (1982) Volcanic ash clusters: tephra rafts and scavengers. J Volcanol Geotherm Res 13:63-71

Sparks RSJ, Bursik MI, Ablay GJ, Thomas RME, Carey SN (1992) Sedimentation of tephra by volcanic plumes, part 2, Controls on thickness and grain-size variation of tephra fall deposits. Bull Volcanol 54:685-695

Stewart C, Johnston DM, Leonard GS, Horwell CJ, Thordarson T, Cronin SJ (2006) Contamination of water supplies by volcanic ash fall: a literature review and simple impact modelling. J Volcanol Geotherm Res 158:296-306

Sugawara H (2017) Volcanic ash supplied from the Aso volcano erupted in October 8, 2016 (Rapid communication). Bull Gunma Mus Nat Hist 21:39-42 (in Japanese)

Taddeucci J, Scarlato P, Montanaro C, Cimarelli C, Del Bello E, Freda C, Andronico D, Gudmundsson MT (2011) Aggregation-dominated ash settling from the Eyjafjallojökull volcanic cloud illuminated by field and laboratory high-speed imaging. Geology 39:891-894

Tokyo Volcanic Ash Advisory Center (2016) Volcanic ash advisories. https:// ds.data.jma.go.jp/svd/vaac/data/Archives/2016_vaac_list.html. Accessed 31 Oct 2018

Van Eaton AR, Herzog M, Wilson CJN, McGregor J (2012) Ascent dynamics of large phreatomagmatic eruption clouds: the role of microphysics. $J$ Geophys Res. https://doi.org/10.1029/2011JB008892

Van Eaton AR, Mastin LG, Herzog M, Schwaiger HF, Schneider DJ, Wallace KL, Clarke AB (2015) Hail formation triggers rapid ash aggregation. Nat Commun 6:7860. https://doi.org/10.1038/ncomms8860

Volentik ACM, Bonadonna C, Connor CB et al (2010) Modeling tephra dispersal in absence of wind: insights from the climactic phase of the 2450 BP Plinian eruption of Pululagua volcano (Ecuador). J Volcanol Geotherm Res 193:117-136

Walker GPL (1981) Characteristics of two phreatoplinian ashes, and their water-flushed origin. J Volcanol Geotherm Res 9:395-407

Walker GPL, Wilson L, Bowell ELG (1971) Explosive volcanic eruptions, I, The rate of fall of pyroclasts. Geophys J R Astron Soc 22:377-383

Watanabe K (1991) Volcanic activity of Nakadake, Aso volcano. J Kumamoto Geosci Assoc 98:2-13 (in Japanese)

Weathernews Inc. (2016) Weathernews Proprietary Infrastructure "WITH Radar" Observed Volcanic Ash Plume from Eruption of Mt. Aso. https://globa I.weathernews.com/news/9978/ Accessed 21 May 2020

Weisner MG, Wetzel A, Catane SG, Listanco EL, Mirabueno HT (2003) Grain size, areal thickness distribution and controls on sedimentation of the 1991 Mount Pinatubo tephra Layer in the South China Sea. Bull Volcanol 67:490-495

Wessel P, Smith WHF (1998) New improved version of generic mapping Tools released. EOS Trans Am Geophys Union 79:579

Yoshimoto T, Shimano T, Nakada S, Koyama E, Tsuji H, Akiko lida, Kurokawa M, Okayama Y, Nonaka M, Kaneko T, Hoshizumi H, Ishizuka Y, Furukawa R, Nogami K, Onizawa S, Niihori K, Sugimoto T, Nagai M (2005) Mass estimation and characteristics of Ejecta from the 2004 eruption of Asama volcano. Kazan 50:519-533 (in Japanese with English abstract)

\section{Publisher's Note}

Springer Nature remains neutral with regard to jurisdictional claims in published maps and institutional affiliations. 